ARTICLE

https://doi.org/10.1038/s41467-018-07806-6

\title{
Interleukin 2 modulates thymic-derived regulatory $T$ cell epigenetic landscape
}

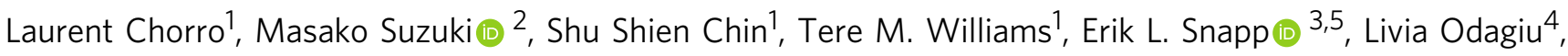
Nathalie Labrecque ${ }^{4} \&$ Grégoire Lauvau (i) ${ }^{1}$

Foxp3 ${ }^{+} \mathrm{CD} 4{ }^{+}$regulatory $\mathrm{T}\left(\mathrm{T}_{\text {reg }}\right)$ cells are essential for preventing fatal autoimmunity and safeguard immune homeostasis in vivo. While expression of the transcription factor Foxp3 and IL-2 signals are both required for the development and function of $\mathrm{T}_{\text {reg }}$ cells, the commitment to the $T_{\text {reg }}$ cell lineage occurs during thymic selection upon $T$ cell receptor (TCR) triggering, and precedes the expression of Foxp3. Whether signals beside TCR contribute to establish $T_{\text {reg }}$ cell epigenetic and functional identity is still unknown. Here, using a mouse model with reduced IL-2 signaling, we show that IL-2 regulates the positioning of the pioneer factor SATB1 in $\mathrm{CD} 4^{+}$thymocytes and controls genome wide chromatin accessibility of thymic-derived $T_{\text {reg }}$ cells. We also show that $T_{\text {reg }}$ cells receiving only low IL-2 signals can suppress endogenous but not WT autoreactive $T$ cell responses in vitro and in vivo. Our findings have broad implications for potential therapeutic strategies to reprogram $T_{\text {reg }}$ cells in vivo.

\footnotetext{
${ }^{1}$ Department of Microbiology and Immunology, Albert Einstein College of Medicine, 1301 Morris Park Avenue, Bronx, NY 10461, USA. ${ }^{2}$ Department of Genetics, Albert Einstein College of Medicine, 1301 Morris Park Avenue, Bronx, NY 10461, USA. ${ }^{3}$ Department of Anatomy and Structural Biology, Albert Einstein College of Medicine, 1301 Morris Park Avenue, Bronx, NY 10461, USA. ${ }^{4}$ Maisonneuve-Rosemont Hospital Research Center and Department of Medicine and Microbiology, Immunology and Infectiology, University of Montreal, 5345 Boulevard de l'Assomption, Montréal, QC H1T 4B3, Canada. ${ }^{5}$ Present address: Janelia Research Campus of the Howard Hughes Medical Institute, Ashburn, VA 20147, USA. Correspondence and requests for materials should be addressed to G.L. (email: gregoire.lauvau@einstein.yu.edu)
} 
$\mathrm{N}$ aturally occurring, thymus-derived Foxp $3^{+} \mathrm{T}_{\text {reg }}$ cells represent a distinct lineage of $\mathrm{CD} 4^{+} \mathrm{T}$ cells which major role is to maintain self-tolerance ${ }^{1-4}$. Foxp3, a forkhead/ winged helix X-linked transcription factor (TF), is the major lineage-specifying TF for these cells and is indispensable for their differentiation, long-term maintenance, and suppressive functions $^{5-7}$. Functional loss of FOXP3 is associated with the rapid onset of fatal $\mathrm{T}$ cell-mediated autoimmunity, also known as the IPEX syndrome in humans (immune dysregulation, polyendocrinopathy, enteropathy, $\mathrm{X}$-linked ${ }^{8}$ ) and the Scurfy phenotype in mice ${ }^{5-7}$. Foxp3 is induced in thymocytes undergoing positive selection following $\mathrm{T}$ cell receptor (TCR) triggering ${ }^{9,10}$ and additional signals such as IL-2, which stabilizes Foxp3 and the associated thymic-derived $\mathrm{T}_{\text {reg }}$ cell program of differentiation $^{11-13}$. The transcriptional regulation of Foxp3 is complex involving the cooperation with multiple additional TFs to enable and maintain $\mathrm{T}_{\text {reg }}$ cell functional attributes ${ }^{10,12,14-16}$. Foxp3 therefore acts as an essential TF, which sustained expression is regulated by three intronic conserved non-coding sequence (CNS) elements (CNS1-3) ${ }^{17}$. CNS3 for instance, acts as a pioneer element in inducing the expression of Foxp3 while CNS2 is bound by IL-2-activated STAT5, directly enabling the stabilization of Foxp3 expression in $\mathrm{T}_{\text {reg }}$ cells ${ }^{18,19}$. The lack of IL-2, its high affinity receptor chain IL-2R $\alpha / C D 25$ or its transducing chain IL-2R $\beta / C D 122^{20}$, lead to the development of wasting autoimmunity as a result of the loss of stable Foxp 3 expression ${ }^{5-7}$ and subsequent Foxp $3^{+} \mathrm{T}_{\text {reg }}$ cells in the periphery ${ }^{21-23}$

While the Foxp3 TF is required to maintain peripheral $\mathrm{T}_{\text {reg }}$ cell identity and functions, it is not sufficient per se to confer the functional attributes of $\mathrm{T}_{\text {reg }}$ cells ${ }^{12,16,24}$, also consistent with twothirds of the $\mathrm{T}_{\text {reg }}$ cell transcriptional signature that cannot be induced by ectopic expression of Foxp 3 in $\mathrm{T}_{\text {conv }}$ cells ${ }^{14,25}$. Studies using Foxp3 fp knock-in/out reporter mice in which GFP $+/+$ thymocytes lacked functional Foxp3, showed that Foxp3 acts to amplify and fix pre-established molecular features of $\mathrm{T}_{\text {reg }}$ cells acquired during thymic selection but prior Foxp3 expression ${ }^{14}$. Foxp $3 G f p / G f p$ thymocytes exhibit CpG hypomethylation patterns characteristic of mature peripheral $\mathrm{T}_{\text {reg }}$ cells $^{24}$. Foxp3 also overwhelmingly binds to pre-existing genome-wide enhancers in thymocytes committed to become $\mathrm{T}_{\text {reg }}$ cells during positive selection $^{26}$. Altogether these findings suggest that TCR-induces epigenetic modifications independently of Foxp3 but likely to involve other transcriptional regulators predefining $\mathrm{T}_{\text {reg }}$ cell identity. Two recent reports provided mechanistic evidence for this concept ${ }^{27,28}$ by showing (i) that the epigenetic modifier SATB1 is essential in activating $\mathrm{T}_{\text {reg }}$ cell-specific super-enhancers associated with Foxp3 and other $\mathrm{T}_{\text {reg-cell signature genes in }}$ thymic precursor $\mathrm{T}_{\text {reg }}$ cells ${ }^{27}$ and (ii) that the methylation enzyme MLL4, which regulates the level of monomethylated H3K4 and chromatin interactions at putative gene enhancers, sets the enhancer landscape for Foxp3 induction via chromatin looping ${ }^{28}$.

These studies represent important conceptual advances in our understanding of the molecular genetics underlying $\mathrm{T}_{\text {reg }}$ celllineage commitment. However, other signals subsequent or concomitant to TCR triggering that may contribute to setting up the functional identity of Foxp $3+\mathrm{T}_{\text {reg }}$ cells are largely unknown. IL-2 is proposed to be essential in this process ${ }^{12,19,21,29}$, but it is believed to be through the stabilization of the Foxp3 TF. Since TCR signaling leads to CD25 upregulation on thymocytes, it is conceivable that IL-2 contributes to establishing thymic $\mathrm{T}_{\text {reg }}$ cell identity in vivo.

Herein, we isolate and characterize a mouse model, the Il2ramut/mut mouse that bears a point mutation in the IL-2 receptor high affinity chain CD25 resulting in a selective and quantifiable decrease in response to only high affinity IL-2 signals, to test the hypothesis that IL-2 signals modulate $\mathrm{T}_{\text {reg }}$ cell epigenetic and transcriptional identity, and subsequent suppressive functions in vivo. Our results suggest that IL-2, possibly through the positioning of the genome organizer SATB1, modulates thymic-derived $\mathrm{T}_{\text {reg }}$ cell epigenetic identity prior to Foxp3 expression. $\mathrm{T}_{\text {reg }}$ cells that integrate low IL-2 signals ( $\mathrm{Il}_{2} \mathrm{ra}^{\text {mut/mut }}$ ) only repress endogenous but not WT autoreactive $\mathrm{T}$ cells, illustrating further the importance of IL-2 signaling for optimal $\mathrm{T}_{\text {reg }}$ cell functions. These observations are consistent with the idea that altering $\mathrm{T}_{\text {reg }}$ cell epigenetic identity, in addition to IL-2 capture and signaling, leads to more rapid autoimmunity, and further raise the possibility that epigenetic reprogramming of $\mathrm{T}_{\text {reg }}$ cells at the time of their selection in the thymus could improve $\mathrm{T}_{\text {reg }}$ cell functions in autoimmune patients.

\section{Results}

Isolation of a novel IL-2 receptor alpha point mutant mouse. During experiments in $C \mathrm{cr} 2^{-1-}$ mice $\mathrm{e}^{30}$ obtained from the Jackson Laboratory (JacksLab) in 2009, referred to as Ccr $2^{-/-} 2009$, we observed that $\mathrm{CD}^{+}{ }^{+}$Foxp $3^{+} \mathrm{T}_{\text {reg }}$ cells in primary and secondary lymphoid organs and blood, displayed low to no cell-surface expression of the IL-2Ra/CD25 compared to $\mathrm{T}_{\text {reg }}$ cells from wild type (WT) B6 counterparts (WT) (Supplementary Fig. 1a). $\mathrm{T}_{\text {reg }}$ cell frequency among $\mathrm{CD} 4^{+} \mathrm{T}$ cells was reduced in spleens and lymph nodes (LNs) while remaining comparable in blood and primary lymphoid organs (Supplementary Fig 1b, c). Since Ccr $2^{-1-}$ mice were neither reported to have different $\mathrm{T}_{\text {reg }}$ cell frequencies nor distinct expression of CD25 compared to WT mice 31,32 , we re-acquired Ccr $2^{-1-}$ mice from the JacksLab in 2012, referred to as $C c r 2^{-/-} 2012$, and compared them to Ccr2 $2^{-/-} 2009$ mice (Fig. 1a). As previously documented, and in contrast to $C c r 2^{-/-} 2009$ mice, $\mathrm{T}_{\text {reg }}$ cell frequencies and CD25 expression were unaltered in $C c r 2^{-/-2012}$ mice. We reasoned that the altered $\mathrm{T}_{\text {reg }}$ cell phenotype could be accounted for by (i) a difference in the skin and/or gut microbiota between the two $C \mathrm{cr} 2^{-/-}$lines, or (ii) a spontaneous mutation acquired in the $C c r 2^{-1-2009}$ colony before 2009. Between 2009 and 2012, Ccr2 $2^{-1-2009}$ mice were backcrossed twice to the WT B6 background and underwent 23 intercrosses (JacksLabs communication). Co-housing of $C \mathrm{cr} 2^{-/-2012}$ and $C \mathrm{Cr} 2^{-/-} 2009$ mice for 3 months neither rescued $\mathrm{T}_{\text {reg }}$ cell frequencies nor expression of CD25 in Ccr2-/- 2009 mice, likely ruling out a microbiota hypothesis (Supplementary Fig. 1d). However, intercross of Ccr $2^{-1-2009}$ and WT B6 mice revealed that $\mathrm{T}_{\text {reg }}$ cells in the F1 offspring expressed twice as less cell-surface CD25 (MFI) compared to $C c r 2^{-/-} 2012 \mathrm{~T}_{\text {reg }}$ cells, but twice as more compared to Ccr2 $2^{-/-} 2009 \mathrm{~T}_{\text {reg }}$ cells, suggesting that the Ccr2 $2^{-/-2009}$ trait is haploinsufficient (Fig. 1b, c). Analysis of CD25 expression levels on $\mathrm{T}_{\text {reg }}$ cells from $51 \mathrm{~F} 2$ offspring obtained from intercrossing $\mathrm{F} 1$ mice revealed a quasi-Mendelian distribution of the various possible phenotypes, consistent with the $C c r 2^{-/-2009}$ trait being controlled by a single gene. Plotting CD25 expression as a function of CCR2 genotypes in the F2 progeny established that CCR2 and CD25 segregated independently of each other with the number of meiosis events close to $50 \%$ (Fig. 1d and Supplementary Fig. 1e). This result suggests that the $C c r 2^{-/-2009}$ trait depends on a single locus likely located on a distinct chromosome than the 9th that carries Ccr2. Whole exome sequencing of Ccr2 $2^{-/-2009}$ and Ccr2 $2^{-/-2012}$ mouse DNA identified only 5 nonsynonymous coding gene variants (Fig. 1e and Supplementary Fig. 1f), with the most relevant coding variant replacing a single thymidine with a cytosine nucleotide on position 426 of exon 4 of the Il2ra gene in the $C c r 2^{-/-2009}$ line. This mutation led to (i) the replacement of an evolutionarily highly conserved tyrosine (Y) with a histidine $(\mathrm{H})$ on position 129 of the $\mathrm{CD} 25$ protein (Fig. 1f), and (ii) the creation a new BssSI restriction site (Supplementary Fig. 1g) which helped confirm the presence of this mutation in Ccr2 $-9-2009$ but not Ccr2 $2^{-1-2012}$ mice. Targeted mutagenesis of the Y129 of WT Il2ra to H129 and retroviral transduction of WT and H129 CD25 in 293T cells (Fig. 1g) recapitulated the CD25 cell-surface expression phenotypes reported in $\mathrm{Ccr} 2^{-/-2009}$ vs Ccr $2^{-1-} 2012$ mice, demonstrating that this point mutation accounted for the mouse phenotype. We next bred mice carrying 
a

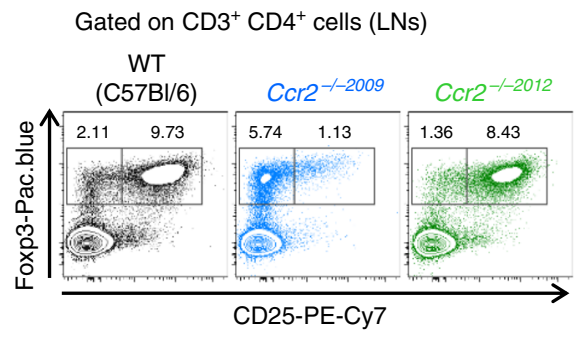

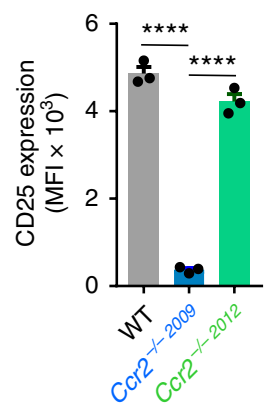

b

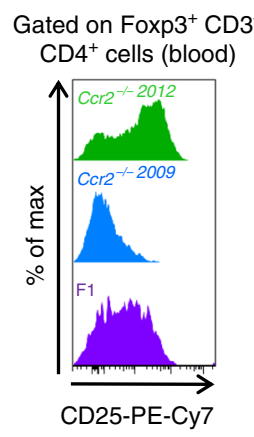

c

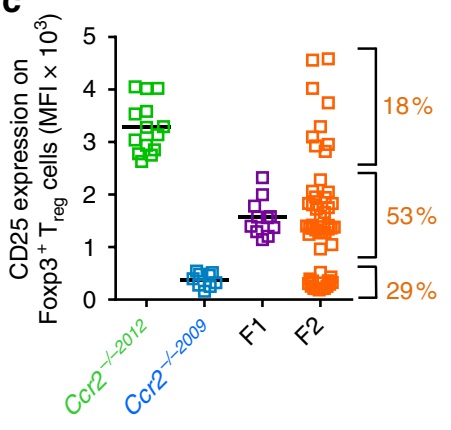

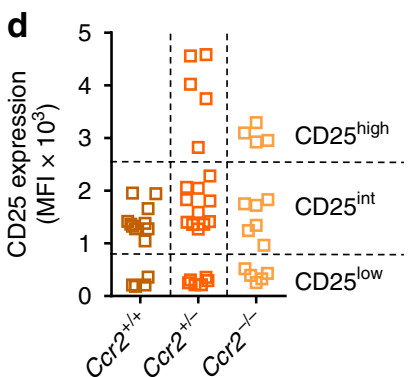

Freq in $\mathrm{F} 2$ offsprings (\%)

\begin{tabular}{|c|c|c|}
\hline 0 & 10 & 8 \\
\hline 20 & 21 & 11.5 \\
\hline 8 & 11.5 & 10 \\
\hline
\end{tabular}

g
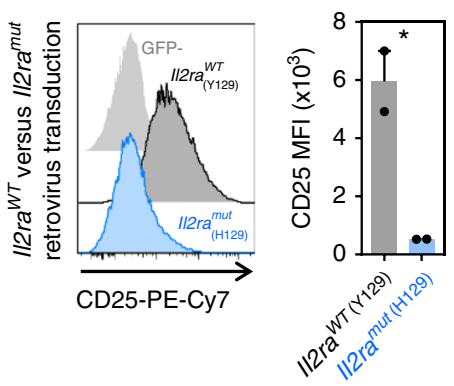

$\mathbf{h}$

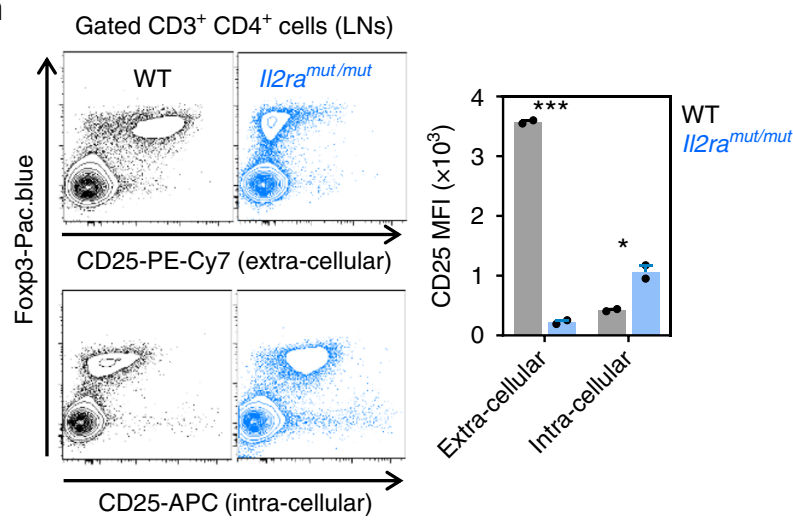

e f

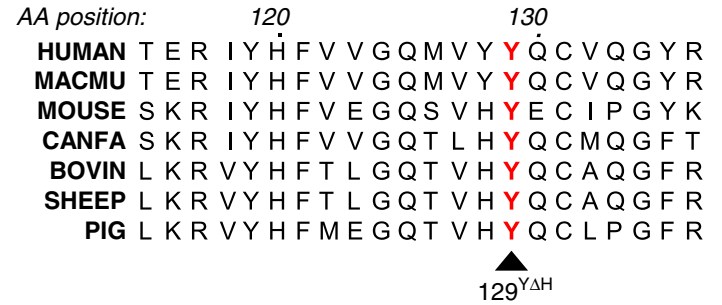

i Anti-CD3 stimulated $\mathrm{CD} 4^{+} \mathrm{T}$ cells $(48 \mathrm{~h})$ Anti-CD25 Anti-Calreticulin Merge

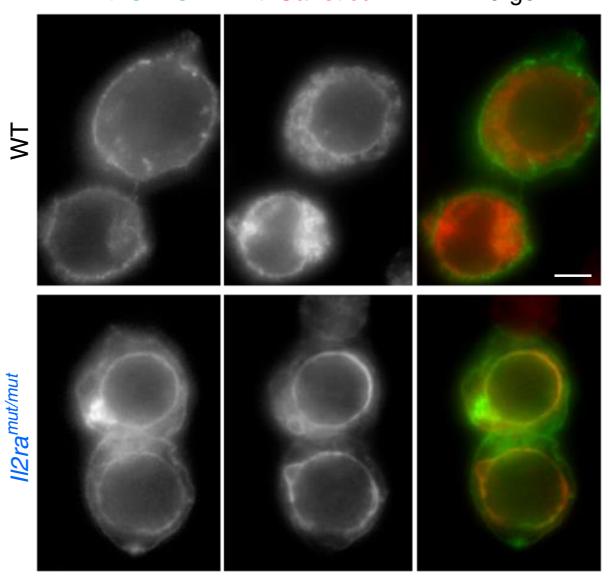

only the homozygous $\mathrm{Y} 129 \mathrm{H}$ mutation from the $\mathrm{Ccr} 2^{+/+} \mathrm{F} 2$ progeny (Fig. 1c), further referred to as $\mathrm{Il} 2 \mathrm{ra}^{\mathrm{mut} / \mathrm{mut}}$ mice.

Since the $\mathrm{Y} 129 \mathrm{H}$ change impaired cell-surface expression of $\mathrm{CD} 25$ on $\mathrm{T}_{\text {reg }}$ cells, we further hypothesized that CD25 may not be properly folded and/or lack stability. Based on the structure of human CD25, which has $\sim 60 \%$ percent homology with mouse CD25, the Y129 likely makes stabilizing hydrogen bonds with a section of CD25 that is in direct contact with IL-2 (Supplementary Fig. 1h). Consistent with this possibility, intracellular staining for CD25 revealed high levels of CD25 inside $\mathrm{T}_{\text {reg }}$ cells from Il2 $\mathrm{ra}^{\mathrm{mut} / \mathrm{mut}}$ compared to WT mice, a finding also confirmed in retrovirally transduced $293 \mathrm{~T}$ cells (Fig. $1 \mathrm{~h}$ and Supplementary
Fig. 1i). CD25 subcellular localization in anti-CD3-stimulated $\mathrm{CD}^{+}{ }^{+} \mathrm{T}$ cells from either Il2 $\mathrm{ra}^{\text {mut } / m u t}$ or WT mice, suggested that mutant CD25 mostly co-localized with calreticulin, an endoplasmic reticulum (ER) resident protein. A strong staining of the nuclear envelope, a subdomain of the ER, was observed in Il2 $\mathrm{ra}^{\text {mut } / m u t}$ but not WT CD4 ${ }^{+} \mathrm{T}$ cells, suggesting that the $\mathrm{Y} 129 \mathrm{H}$ mutation prevented proper folding of CD25 and subsequent egress from the ER to the cell surface (Fig. 1i). Thus, we isolated and characterized a mouse mutant line with a point mutation in an evolutionarily highly conserved tyrosine of the high affinity IL2 receptor alpha chain CD25, likely preventing its optimal folding and subsequent cell-surface expression. 
Fig. 1 Isolation and characterization of the II2ramut/mut mouse model. a Lymph node cells isolated from WT, Ccr2-/-2009 and Ccr2-/-2012 (all on the B6 background) mice were stained with mAbs against cell-surface CD3, CD4, CD25 (clone PC61), and intracellular Foxp3. A representative dot plot is shown. Bar graph summarizes CD25 expression levels (MFI) across all mice analyzed. b FACS histograms of cell-surface CD25 levels (MFI) gated on blood Foxp3 ${ }^{+} \mathrm{T}_{\text {reg }}$ cells $\left(\mathrm{CD}^{+} \mathrm{CD}^{+}\right)$from $\mathrm{Ccr}^{-/-2009}, \mathrm{Ccr}^{-/-2012}, \mathrm{Ccr} 2^{+/-2009}$ (F1) mice. c Distribution of CD25 cell-surface expression levels (MFI) in $\mathrm{T}_{\text {reg }}$ cells from the blood of individual mice of indicated genotypes including $\mathrm{Ccr} 2^{+/-2009} \times \mathrm{Ccr}^{+/-2009}$ (F2) mice. d Ccr2 genotypes based on CD25 surface expression levels and experimental frequencies obtained in F2 offsprings. e DNA and corresponding amino-acid sequence alignments of the mutation found in exon 4 of $112 \mathrm{ra}$ gene in $\mathrm{Cr} 2^{-/-2009}$ vs C cr2 $-/-2012$ mice after whole-exome sequencing. $\mathbf{f}$ Alignment of the CD25 amino-acid sequence surrounding tyrosine 129 across multiple species. $\mathbf{g}$ FACS histograms of cell-surface expression of CD25 in 293 T cells retrovirally transduced with WT or mutagenized $\mathrm{Y} 129 \mathrm{H}$ II2ra cDNA. Bar graph shows CD25 expression (MFI) across two independent transduction experiments. $\mathbf{h}$ Dot plots of cell-surface or intracellular expression levels (MFI) of CD25 in WT and mutant $\mathrm{T}_{\text {reg }}$ cells. Bar graphs average data from one of 2-3 experiments with similar results with $>2$ mice per group. i Fluorescent microscopy staining of CD25 on anti-CD3 stimulated purified CD4 ${ }^{+} \mathrm{T}$ cells isolated from LNs. T cells were fixed and co-stained with anti-CD25 (green) and anti-calreticulin (red) prior to image acquisition. Scale bar is $5 \mu$ m. $p$-values are indicated when relevant with ${ }^{\star} p<0.05 ;{ }^{\star \star} p<0.01 ;{ }^{\star \star \star} p<0.001$; NS not significant, using two-tailed unpaired Student's $t$-test. Error bars are mean \pm SEM in all figures

Il2ra ${ }^{m u t} / m u t ~ T$ cells exhibit impaired responses to IL-2. We next assessed whether impaired cell-surface expression of CD25 on $\mathrm{T}$ cells translates into decreased IL-2 binding and signaling. Using labeled IL-2 incubated with anti-CD3 stimulated CD4 ${ }^{+} \mathrm{T}$ cells, we found higher IL-2 binding to WT compared to either Il2ra ${ }^{\text {mut }}$ / $m u t$ or WT T cells incubated with an excess of non-biotinylated IL-2 (Fig. 2a and Supplementary Fig. 2a). STAT5a phosphorylation, a very early signaling response that follows IL-2 binding to CD25, was also profoundly altered both in $\mathrm{T}_{\text {reg }}$ cells from thymus and LNs and in conventional CD4 ${ }^{+} \mathrm{T}\left(\mathrm{T}_{\text {conv }}\right)$ cells from Il2 $\mathrm{ra}^{\text {mut }}$ mut mice (Fig. 2b and Supplementary Fig. 2a, b). Consistent with these findings, Il2ramut/mut $\mathrm{CD}^{+}$and $\mathrm{CD} 4^{+} \mathrm{T}_{\text {conv }}$ cells proliferated substantially less compared to WT counterparts as quantified in vitro by CTV dilution of labeled $\mathrm{T}_{\text {conv }}$ cells after anti-CD3 and varied amounts of IL-2 (Fig. $2 c$ and Supplementary Fig. 2a, c). To extend findings in vivo, we next monitored CD25 upregulation on $\mathrm{K}^{\mathrm{b}} / \mathrm{Ova}_{257-264}$ tetramer $^{+}\left(\mathrm{Tet}^{+}\right) \mathrm{CD}^{+} \mathrm{T}_{\text {conv }}$ cells primed in WT or Il2ramut/mut mice infected intravenously (i.v.) with Listeria monocytogenes expressing the model antigen Ovalbumin (Lm-Ova) (Fig. 2d). Expression of CD25 by Ova-specific $\mathrm{Tet}^{+} \mathrm{CD}^{+} \mathrm{T}_{\text {conv }}$ cells was lower in Il2 $\mathrm{ra}^{\text {mut } / m u t}$ compared to WT mice ${ }^{33}$, in line with the in vitro data (Fig. 2d). Then, we generated mixed bone-marrow chimeras from lethally irradiated recipient mice reconstituted with WT and Il2ramut/mut donor bone-marrow cells (ratio 1:1) so that we could monitor and compare WT and Il2ra ${ }^{m u t / m u t}$ antigen-specific $\mathrm{CD} 8^{+} \mathrm{T}_{\text {conv }}$ cell responses in the same host (Fig. 2e and Supplementary Fig. 2d). Reconstituted chimeras were further infected with Lm-Ova or the Herpes Simplex Virus 2 (HSV-2) intravaginally (i.vag.), and both $\mathrm{K}^{\mathrm{b}} / \mathrm{Ova}_{257-264}$ and $\mathrm{K}^{\mathrm{b}} / \mathrm{gB}_{498-505}$ Tet $^{+} \mathrm{T}_{\text {conv }}$ cells were monitored at the peak of the primary response. In both models, Ova- and gB-specific Il2ra ${ }^{\text {mut } / m u t} \mathrm{CD} 8{ }^{+} \mathrm{T}_{\text {conv }}$ cells expanded $\sim 3$-fold less than WT counterparts. Thus, the CD25 Y129H mutation profoundly alters CD25 expression and functional response to IL-2 in both $\mathrm{T}_{\text {conv }}$ and $\mathrm{T}_{\text {reg }}$ cells.

IL-2 modulates $T_{\text {reg }}$ cell epigenetic landscapes. IL-2 signals are postulated to contribute to establishing the $\mathrm{T}_{\text {reg }}$ cell program of differentiation before $\mathrm{T}_{\text {reg }}$ cells express Foxp3 in the thymus ${ }^{11-13,34}$ but only little evidence exist to support this hypothesis. To explore this possibility, we took advantage of the

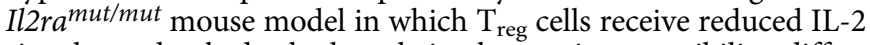
signals, and asked whether their chromatin accessibility differs just after they have committed to the $\mathrm{T}_{\text {reg }}$ cell lineage (thymus) and in the periphery in the secondary lymphoid organs (LNs). We isolated Foxp3 $3^{+} \mathrm{T}_{\text {reg }}$ cells from thymus and LNs of Il2 $\mathrm{ra}^{\text {mut }}$ / $m u t$ and WT Foxp $3^{R f p} / R f p$ reporter mice and conducted an analysis of the genome-wide open chromatin regions (OCRs) using an assay for transposase accessible chromatin with high-throughput sequencing (ATAC-seq ${ }^{35}$, Fig. 3 and Supplementary Fig. 3). While we found 36,200 and 32,369 OCRs (ATAC-seq peaks) in WT and Il2rat $\mathrm{rut}^{\text {mut }}$ thymic $\mathrm{T}_{\text {reg }}$ cells respectively, $\mathrm{LN} \mathrm{T}_{\text {reg }}$ cells exhibited 25,167 and 24,639 OCRs (Fig. 3a). Ninety-five percent of WT LN $\mathrm{T}_{\text {reg }}$ cell OCRs identified overlapped with those reported in a prior study analyzing $\mathrm{LN} \mathrm{T}_{\text {reg }}$ cell OCRs ${ }^{36}$ (Supplementary Fig. 3a). As expected, this overlap was lower (75-80\%) when we compared WT $\mathrm{T}_{\text {reg }}$ cell's OCRs to that reported in $\mathrm{CD}^{+} \mathrm{T}$ cells ${ }^{37}$. Within the thymic and $\mathrm{LN} \mathrm{T}_{\text {reg }}$ cell OCRs, we respectively identified 8031 and 8484 differentially accessible OCRs in WT (5931 in thymus and 4506 in LN) and Il2ra ${ }^{\text {mut } / m u t}$ (2100 in thymus and 3978 in LN) $\mathrm{T}_{\text {reg }}$ cells (Fig. 3a). This represents $\sim 41 \%$ difference in the epigenetic landscape of WT vs Il2rat ${ }^{\text {mut } / m u t} \mathrm{LN} \mathrm{T}_{\text {reg }}$ cells, which is comparable to what is reported between resting and activated $\mathrm{T}_{\text {reg }}$ cell OCRs ${ }^{36}(\sim 36 \%$, Supplementary Fig. 3b). These differences are also similar to those measured between effector and memory or exhausted $\mathrm{CD}^{+}$ $\mathrm{T}$ cells (34-41\%) ${ }^{37-39}$ but substantially greater than that reported in effector cells isolated from mice infected with acute vs chronic LCMV $(\sim 15 \%)^{38}$. Analysis of the relative localizations of differential OCRs in relation to the mouse ensemble annotated genes revealed a lower proportion of OCRs in the transcription start sites (TSS, $\leq 1 \mathrm{~kb}$ ) compared to that of the overlapping peaks both for thymic and $\mathrm{LN} \mathrm{T}_{\text {reg }}$ cells ( 9-14\% vs $37-48 \%$, Fig. $3 \mathrm{~b}, \mathrm{c}$ and Supplementary Fig. $3 \mathrm{c}$ and Data 1). The majority of unique peaks were found in introns and distal intergenic regions $(>10 \mathrm{~kb})$, suggesting that IL-2 signals regulate chromatin opening of elements distal to the TSS already at early stages of $\mathrm{T}_{\text {reg }}$ cell commitment in the thymus. Upon assigning these peaks to the closest gene TSS, 651 (thymus) and 762 (LN) genes with differential OCRs were common to WT and Il2 $\mathrm{ra}^{\mathrm{mut} / \mathrm{mut}} \mathrm{T}_{\text {reg }}$ cells while the remaining were within non-overlapping genes (Fig. $3 \mathrm{~d}$ and Supplementary Data 2). Approximately three times as many genes and OCRs were uniquely present in WT compared to Il $2 \mathrm{ra}^{\text {mut } / \text { mut }}$ thymic $\mathrm{T}_{\text {reg }}$ cells (3401 vs 1107 genes) while $\mathrm{LN} \mathrm{T}_{\text {reg }}$ cells had comparable numbers of unique genes and OCRs (2356 vs 1992 genes)(Fig. 3a,d). This result shows that the ratio of differential OCRs between WT and Il2 $\mathrm{ra}^{\text {mut } / m u t} \mathrm{~T}_{\text {reg }}$ cells from the thymus to the LNs is substantially modulated (from $\sim 3: 1$ to $1: 1)$, suggesting further functional commitment of $\mathrm{T}_{\text {reg }}$ cells. Analysis of the biological-process (BP) gene-ontology (GO) pathways of genes containing unique peaks $(<20 \mathrm{~kb}$ from TSS) in WT thymic and LN $\mathrm{T}_{\text {reg }}$ cells highlighted a much greater diversity of BP (251 and $356 \mathrm{GO}$ pathways vs only 86 and 14 GO pathways, respectively)(Fig. 3e and Supplementary Data 3 ). Since the differences in the number of genes with unique peaks between WT and Il2ramut/mut $\mathrm{T}_{\text {reg }}$ cells is much smaller compared to that of the GO pathways (Fig. 3d, e), it further suggests that the OCRs in Il2ra ${ }^{m u t / m u t} \mathrm{~T}_{\text {reg }}$ cells are more random. While some processes related to $\mathrm{T}$ cell activation and tolerance are common to both types of $\mathrm{T}_{\text {reg }}$ cells in the thymus, others targeting activation, migration and effector mechanisms are only maintained in WT $\mathrm{LN} \mathrm{T}_{\text {reg }}$ cells (Fig. 3f). Conducting the GO pathway analysis on genes containing unique peaks without any limit from TSS 


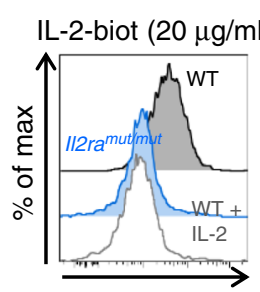

IL-2-biot+SA-PE

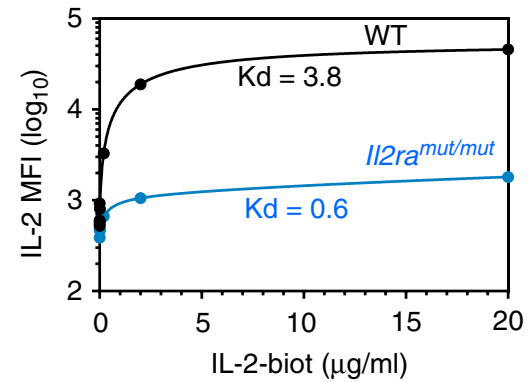

b Gated on $\mathrm{CD}^{+} \mathrm{CD}^{+} \mathrm{Foxp}^{+}$cells from $\mathrm{LNs}$ Anti-CD3 stimulated CD4 ${ }^{+} \mathrm{T}$ cells $(48 \mathrm{~h})$
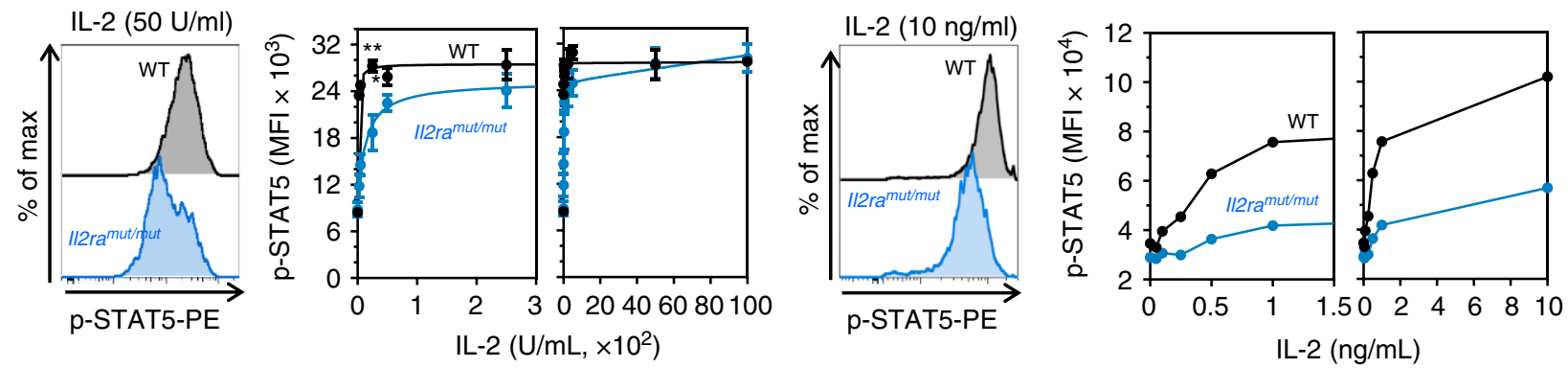

C

Gated on $\mathrm{CD}^{+} \mathrm{CD}^{+} \mathrm{T}$ cells
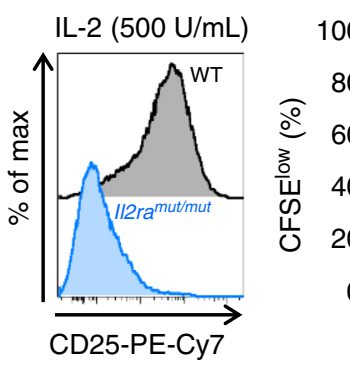

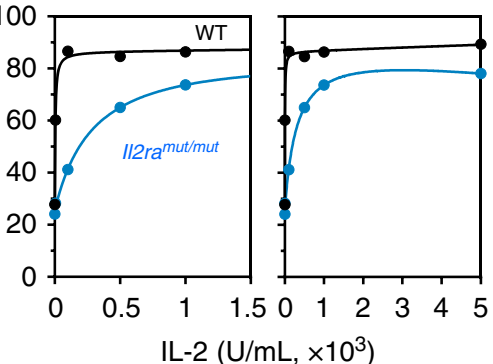

$\mathrm{IL}-2\left(\mathrm{U} / \mathrm{mL}, \times 10^{3}\right)$
Gated on $\mathrm{CD}^{+} \mathrm{CD}^{+} \mathrm{T}$ cells
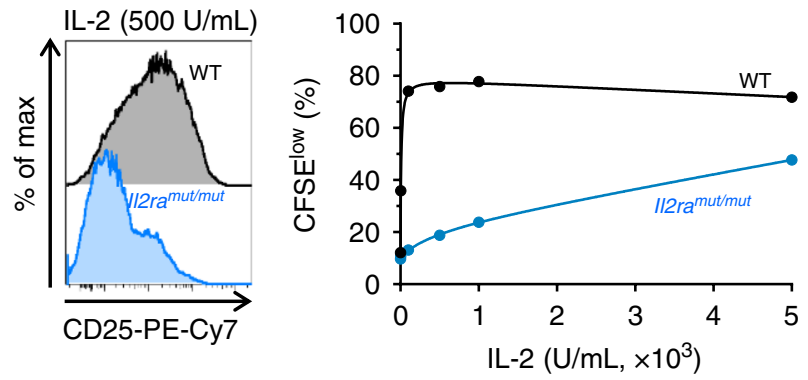

\section{d}

L.m.-Ova infection

Gated on $\mathrm{CD}^{+} \mathrm{CD}^{+} \mathrm{Kb} / \mathrm{Ova}_{257-264}$ (Tet) ${ }^{+}$cells
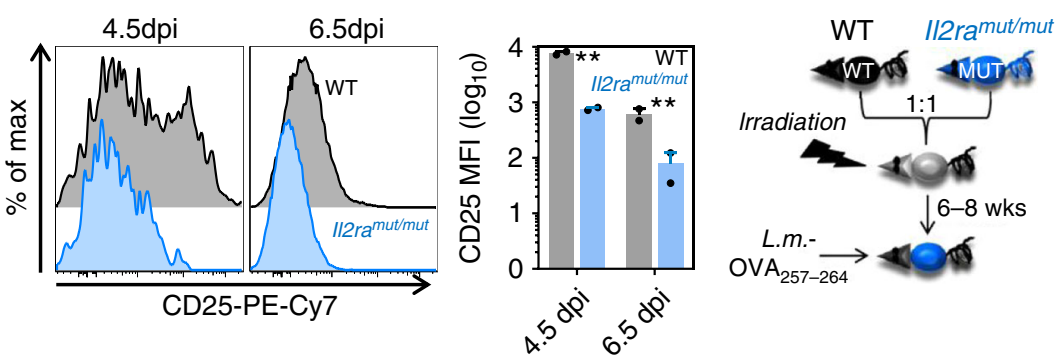

Gated on $\mathrm{CD}^{+} \mathrm{T}$ cells, $7.5 \mathrm{dpi}$
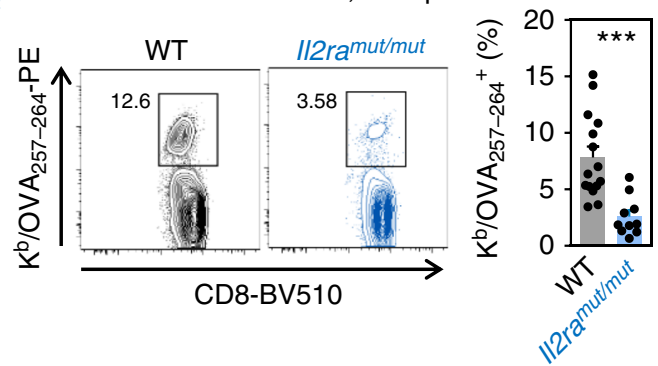

revealed the exact same trend (Supplementary Fig. S3d,e and Data 3). Thus, IL-2 signals have a broad impact on genomewide $\mathrm{T}_{\text {reg }}$ cell epigenetic landscape, both for the opening and the closing of mostly TSS-distant regulatory regions. IL-2mediated alterations occur already at early stages of $\mathrm{T}_{\text {reg }}$ cell commitment to this lineage in the thymus and are sustained throughout $\mathrm{LN} \mathrm{T}_{\text {reg }}$ cells.

IL-2-driven epigenetic changes mildly alter gene expression. Since IL-2 induces extensive modifications in the chromatin of $\mathrm{T}_{\text {reg }}$ cells (Fig. 3), we next assessed whether these alterations translated into a distinct program of expression between $\mathrm{Il}_{2} \mathrm{ra}^{\mathrm{mut} /}$ $m u t$ and WT LN $\mathrm{T}_{\text {reg }}$ cells. The lack of IL-2 signaling in $\mathrm{T}_{\text {reg }}$ cells was reported to only alter a relatively focused set of genes implicated in cell growth, metabolism, motility and adhesion, preventing their overall competitive fitness in vivo $21,29,40$. We purified total RNA from flow-sorted Foxp $3^{+}\left(\mathrm{RFP}^{+}\right) \mathrm{T}_{\text {reg }}$ or naive (CD62 $\mathrm{L}^{\text {hi CD44 }}{ }^{\mathrm{lo}}$ ) $\mathrm{T}_{\text {conv }}$ cells isolated from the $\mathrm{LNs}$ of WT or $I l 2 \mathrm{ra}^{\mathrm{mut} / \mathrm{mut}} \mathrm{Foxp} 3^{R f p / R f p}$ reporter mice, and analyzed gene expression using microarrays (Fig. 4). While the expression profiles of naive $\mathrm{T}_{\text {conv }}$ cells are almost identical between the two groups, that of $I l 2 \mathrm{ra}^{\mathrm{mut} / \mathrm{mut}}$ and WT $\mathrm{T}_{\text {reg }}$ cells exhibit significantly more differences (Fig. 4a and Supplementary Fig. 4a and Data 4). We note a set of 277 differentially expressed genes among which 128 and 149 are up- or downregulated respectively in $\mathrm{Il} 2 \mathrm{ra}^{\mathrm{mut} / \mathrm{mut}}$ compared to WT $\mathrm{T}_{\text {reg }}$ cells (Fig. $4 \mathrm{~b}$ and Supplementary Fig. $4 \mathrm{~b}$ ). 
Fig. 2 The Y129H mutation in CD25 impairs IL-2 binding, signaling and T cell proliferation. a Recombinant human IL-2 was biotinylated and incubated with anti-CD3 stimulated purified CD4+ ${ }^{+}$cells from II2ramut/mut or WT mice prior to staining with streptavidin PE. Unbiotinylated IL-2 was added to WT T cells as a control of binding specificity. Representative FACS histograms of IL-2 or no IL-2 bound to mutant or WT T cells are shown. The graph plots IL-2 binding signals (MFI) with increasing concentration of biotinylated IL-2. IL-2 Kd (50\% binding capacity) for II2ramut/mut or WT T cells are shown. b Purified CD4 ${ }^{+}$T cells from LNs of $I / 2 r^{\text {mut }} /$ mut or WT mice $(n=3)$ were incubated in serum-free media $\left(30^{\prime}\right)$ and with IL-2 (20') before proceeding to intracellular STAT5 phosphorylation staining. FACS histograms of STAT5 phosphorylation levels in Foxp $3^{+} \mathrm{T}_{\text {reg }}$ (left) and anti-CD3 activated CD4 ${ }^{+} \mathrm{T}_{\text {conv }}$ (right) cells are shown. Graphs plot phosphorylated STAT5 expression with increased IL-2 concentrations. c Purified LN CD4+ or CD8 ${ }^{+} \mathrm{T}$ cells from II2ramut/mut or WT mice were CFSE-labeled and incubated with anti-CD3 and IL-2. The proportion of CFSElow T cells was determined by FACS 4 days later. Graphs plot the \% CFSElow T cells as IL-2 increases in 1 of 3 replicate experiments. FACS histograms show cell-surface CD25 expression in II $2 \mathrm{ramut} / \mathrm{mut}$ or WT T cells 4 days post IL-2 incubation. d II2ramut/mut or WT mice $(n=2)$ were immunized i.v. with $10^{4}$ WT Listeria monocytogenes ( Lm) expressing Ovalbumin ( Lm-Ova) and spleen cells were stained at indicated days with $\mathrm{Ova}_{257-264} / \mathrm{K}^{\mathrm{d}}$ tetramers $\left(\mathrm{Tet}^{+}\right.$) and anti-CD25. Representative FACS histograms of CD25 expression on tet ${ }^{+} \mathrm{CD}^{+} \mathrm{T}$ cells is shown with a summary bar graph. e WT/II2ra mut/mut mixed bone-marrow (BM) chimeras (ratio 1:1) with discriminative CD45.1/2 congenic markers were immunized i.v. with WT Lm-Ova and 7.5 days later spleen cells stained with $\mathrm{Ova}_{257-264} / \mathrm{K}^{\mathrm{d}}$ tetramers. Representative FACS dot plots and summary bar graphs of $L m$-specific $112 \mathrm{ra} \mathrm{aut}^{\mathrm{mu}} \mathrm{mut}$ or WT tet ${ }^{+} \mathrm{CD} 8^{+} \mathrm{T}$ cells are shown $(n=15$ mice $)$. $p$-values are indicated with ${ }^{\star} p<0.05$; ${ }^{\star \star} p<0.01 ;{ }^{\star \star \star} p<0.001$; NS not significant, using two-tailed unpaired Student's $t$-test. Error bars are mean \pm SEM in all figures

These genes are involved in cellular adhesion and cytoskeleton rearrangement, cell division and differentiation, cytokines and receptors, cellular activation and chemotaxis (Fig. 4c), consistent with prior reports $21,29,40$. We checked some of the differentially upregulated genes for which Abs specific for encoded proteins are available, and found a direct correlation with protein expression levels for KLRG1, TIGIT, CCR4 while we did not for CCR5 or BTLA (Supplementary Fig. 4c). Interestingly, increased expression of these markers is detected only in a small subset of $\mathrm{CD}^{+} \mathrm{T}_{\text {reg }}$ cells, suggesting that lowering IL-2 signals promotes the onset of a subpopulation of $T_{\text {reg }}$ cells with a slightly distinct expression program, rather than altering the whole $\mathrm{T}_{\text {reg }}$ cell population. Since only a few of the downregulated genes encode for proteins of known functions, we next focused primarily on sets of upregulated genes to run a comparison against known BP-GO databases (Fig. 4d and Supplementary Fig. 4d,e and Data 5). We found statistically over-represented gene sets implicated in cell adhesion, activation, proliferation/cell cycle, cellular differentiation as well as inflammatory processes, transcriptional regulators and chromatin organization/epigenetic gene regulation. While only a limited set of genes are differentially expressed in Foxp $3^{+} \mathrm{T}_{\text {reg }}$ cells that receive lower IL-2 signals, the biological functions that are altered seem to directly target their ability to migrate, undergo homeostatic proliferation and express suppressive effector functions. We also noted differences in expression of genes implicated in various steps of chromatin modifications (Supplementary Fig. 4f).

Most interestingly, although the number (4875) and relative

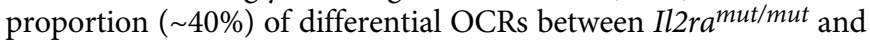
WT LN $\mathrm{T}_{\text {reg }}$ cells is important (Fig. 3), those of differentially expressed genes (266) remain very small (below $1 \%$ of genes), suggesting that IL-2 signals play a more prominent role in shaping the epigenetic landscape and identity of $\mathrm{T}_{\text {reg }}$ cells than their ability to express sets of genes (Fig. $4 \mathrm{e}$ and Supplementary Data 6). Among the differentially expressed genes, only 72 exhibited unique OCRs in either WT or Il2ra ${ }^{\text {mut } / m u t} \mathrm{LN} \mathrm{T}_{\text {reg }}$ cells. These OCRs may contribute to the changes in gene expression via chromatin structure modifications while the remaining genes (194) are likely to be controlled at the level of gene transcription with no changes in chromatin structures. For instance, CD80 that is highly expressed in Il2ra ${ }^{\text {mut } / m u t}$ compared to WT LN T $\mathrm{T}_{\text {reg }}$ cells, exhibits greater OCRs heights in Il2ramut/mut vs WT $\mathrm{T}_{\text {reg }}$ cell promoter regions (Fig. 4f). Differential OCRs are further noted in intergenic regions of KLRG1 or in intronic regions for TIGIT. Interestingly, neither the Foxp 3 nor the Helios genes had differential OCRs between Il2ramut/mut and $\mathrm{WT} \mathrm{T}_{\text {reg }}$ cells (Supplementary Fig. 4g and Data 7). Analysis of the potential binding motifs for TFs in the differential OCRs revealed that a different set of TFs such as FOXO and KLF family members, could possibly bind in WT but not Il2ra ${ }^{\text {mut } / m u t} \mathrm{~T}_{\text {reg }}$ cells (Supplementary Fig. 4h). Because chromatin structures in the vicinity of TSS regions play critical roles in the expression status of the gene, we tested if differentially expressed genes contain differential OCRs close to the TSS (Fig. 4g and Supplementary Data 6). Eleven differentially expressed genes contain differential OCRs close to their TSS $( \pm 500 \mathrm{bp})$ while the majority of the remaining genes did not, suggesting that these genes undergo epigenetic modifications mostly occurring on elements distal to the TSS such as gene enhancer regions. In summary, despite establishing major genome wide changes of the $\mathrm{T}_{\text {reg }}$ cell epigenetic landscape, IL-2 signals on LN $\mathrm{T}_{\text {reg }}$ cells at steady state only translate in modest modifications of their gene expression profiles.

IL-2 regulates SATB1 positioning prior $T_{\text {reg }}$ cell commitment. We next investigated how IL-2 signals mediate such large genome-wide changes in the $\mathrm{T}_{\text {reg }}$ cell epigenome. Given its essential role in $\mathrm{T}_{\mathrm{reg}}$ cell-lineage specification and functions $\mathrm{s}^{5-7,14}$, and its dependence on IL-2 ${ }^{19,21}$, one obvious candidate is the Foxp3 TF. If Foxp3 accounted for our observations, we predicted that Foxp3 binding regions would exhibit a very large overlap with the OCRs found in WT $\mathrm{T}_{\text {reg }}$ cells but less with that of Il2ra ${ }^{\text {mut } / m u t} \mathrm{~T}_{\text {reg }}$ cells (Supplementary Fig. 5a). By aligning published chromatin immunoprecipitation sequencing (ChIP-seq) results of the Foxp3 TF defining the Foxp3 binding sites throughout the genome of $L N \mathrm{~T}_{\text {reg }}$ cells ${ }^{26}$ with our ATAC-seq data, we found that Foxp3 DNA binding regions largely overlapped with OCRs common between Il2ramut/mut and WT LN $\mathrm{T}_{\text {reg }}$ cells, suggesting that IL-2-mediated alterations of the $\mathrm{T}_{\text {reg }}$ cell epigenome are independent of Foxp3. Robust experimental evidence supports the idea that $T_{\text {reg }}$ cell epigenetic and functional identity is established in the thymus prior $\mathrm{T}_{\text {reg }}$ cells express Foxp3 $3^{1324-26}$. Notably, the pioneer factor SATB1 was reported to be essential for $\mathrm{T}_{\text {reg }}$ cell-lineage specification before expression of Foxp3 in the thymus but not after ${ }^{27}$. Thus, we hypothesized that IL-2 acts through SATB1 before thymocytes commit to the $\mathrm{T}_{\text {re }}$ cell fate, at the single positive (SP) CD4 $4^{+}$thymocyte stage ${ }^{11,13,24}$. We know (Fig. 3) that mature Foxp3 ${ }^{+}$Il2ra ${ }^{m u t / m u t}$ thymic $\mathrm{T}_{\text {reg }}$ cells already exhibit differential OCRs compared to WT counterparts, suggesting epigenetic changes may have occurred before this stage. We conducted ChIP-seq experiments of SATB1 on SP $\mathrm{CD}^{+}$thymocytes isolated from Il2ra $\mathrm{rut}^{\mathrm{mut}}$ or WT mice, postulating that SATB1 DNA positioning would differ if indeed this pioneer factor is involved in the regulation of IL-2-mediated $\mathrm{T}_{\text {reg }}$ cell epigenetic changes (Fig. 5). The vast majority of SATB1bound regions in WT and Il2ramut/mut SP CD4 ${ }^{+}$thymocytes overlapped. While only 123 unique DNA regions are bound by SATB1 in WT thymocytes, SATB1 associate to more than $50 \%$ 
a

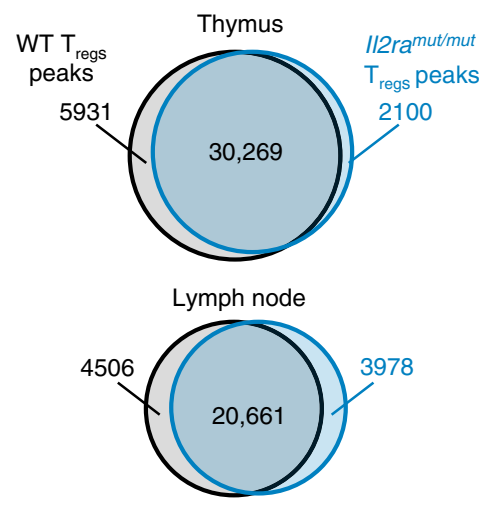

C

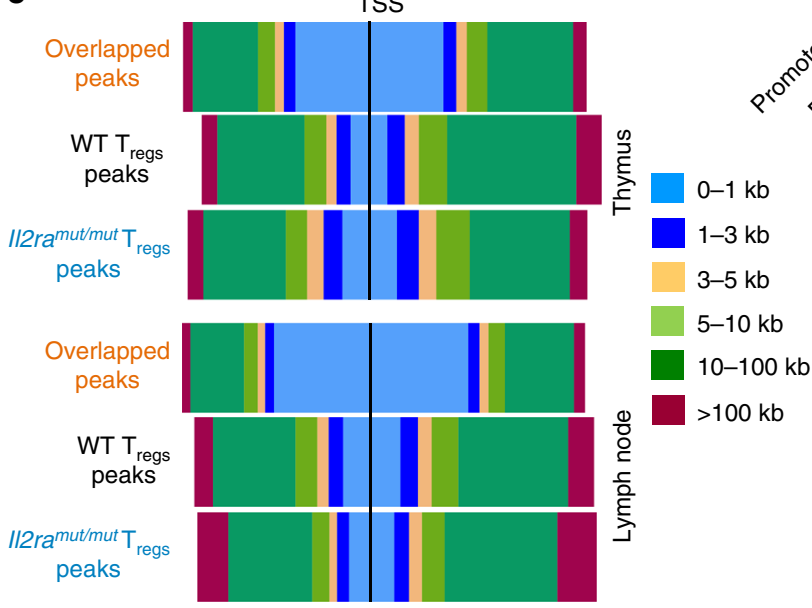

b

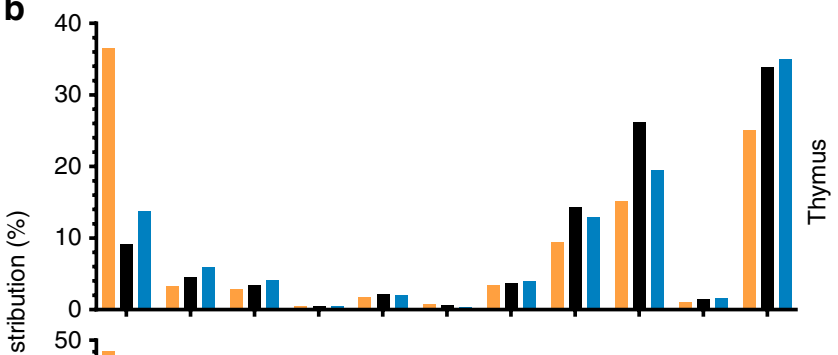

OS 50 Overlapped peaks

WT 40 regs peaks

30.112 ramutmut $^{\text {megs }} T_{\text {regs }}$ peaks
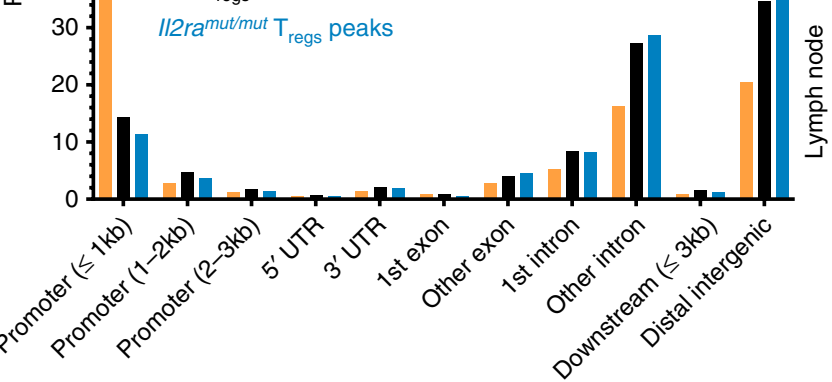

$\frac{0}{\circ}$

f

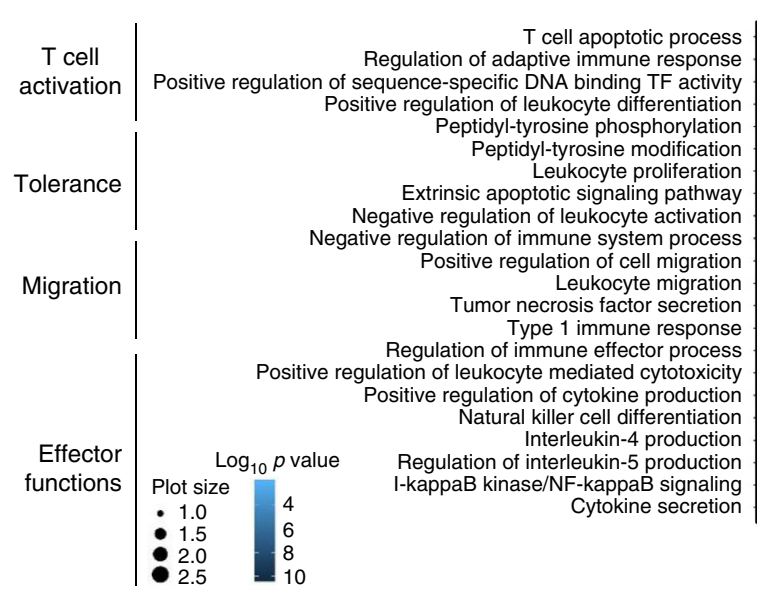

d

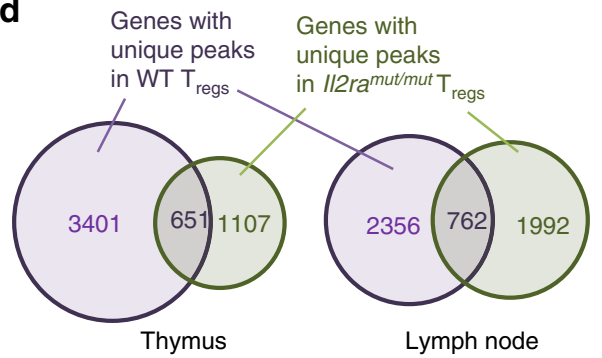

e

BP-GO terms from genes BP-GO terms from with unique peaks genes with unique peaks in WT Tr

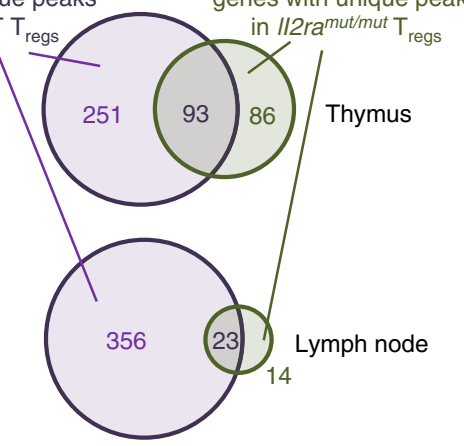

Fig. 3 IL-2 makes substantial modifications in the epigenetic landscape of $T_{\text {reg }}$ cells: $T_{\text {reg }}$ cells $\left(5 \times 10^{4}\right)$ were sorted by flow cytometry from thymus or LNs of $112 \mathrm{ramut} / \mathrm{mut}^{\mathrm{m}}$ and WT Foxp3Rfp/Rfp reporter mice, lysed and DNA from nucleus extracted for analysis of open chromatic regions by ATAC-seq. a Venn diagram of number of common and unique ATAC-seq peaks (OCRs) in II2ramut/mut vs WT Treg cells from thymus and LNs. $\mathbf{b}, \mathbf{c}$ Distribution of common and unique ATAC-seq peaks across gene organization (b) and distance to the transcription start site (TSS, c) in the whole genome. d, e Venn diagrams of number of genes (d) and GO pathways (e) exhibiting unique peaks in $1 / 2 \mathrm{ramut} / \mathrm{mut}$ vs WT thymic and LN $\mathrm{T}_{\text {reg }}$ cells on all (d) or within (e) $20 \mathrm{~kb}$ from TSS. f Network analysis of biological-process GO term enrichment among genes with unique peaks within $20 \mathrm{~kb}$ from TSS in $1 / 2 \mathrm{ramut} / \mathrm{mut}$ or WT thymic and LN $\mathrm{T}_{\text {reg }}$ cells. Genes were analyzed for over-represented GO terms using ReviGO. Node color is proportional to the FDR-adjusted p-value of the enrichment. Node size is proportional to gene set size 
a

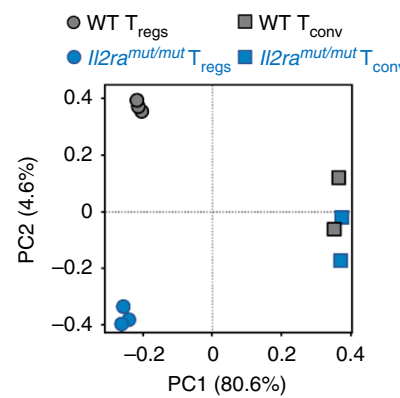

b

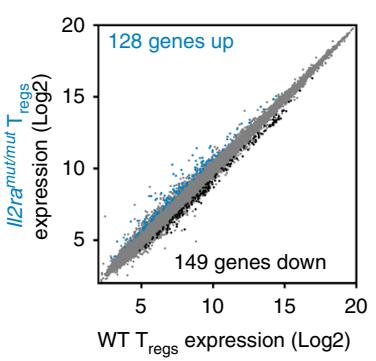

d

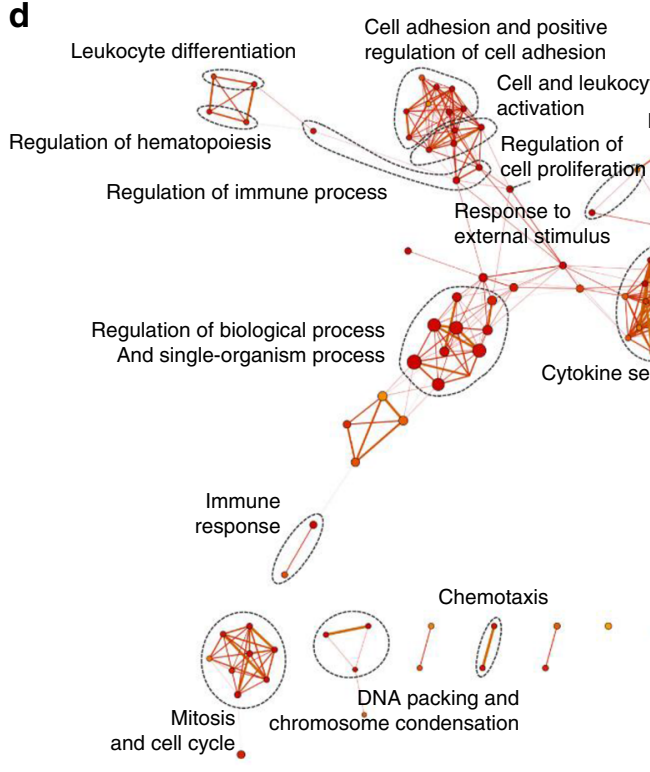

f)

Regulation of production of IFN $\gamma$ Regulation of production
of TNF

e

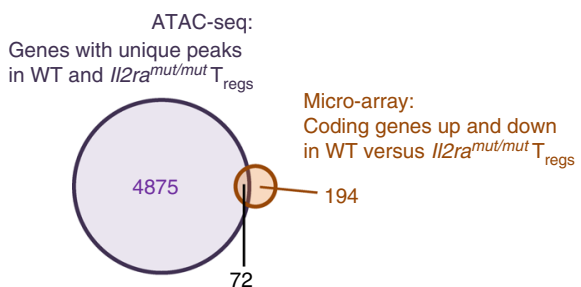

g

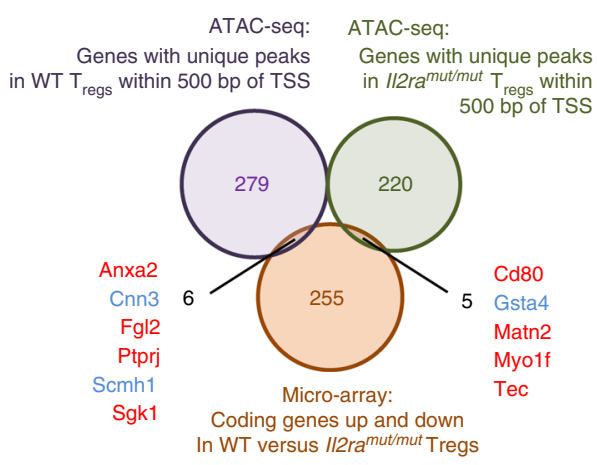

additional regions (2929) in Il2ra $\mathrm{rut}^{\mathrm{mut}}$ thymocytes, showing that ectopic binding of this pioneer factor occurs when IL-2 signals are limiting (Fig. 5a). Interestingly, the 123 unique SATB1-binding regions in WT thymocytes localize closer to promoter areas compared to that of $I l 2 \mathrm{ra}^{\mathrm{mut} / \mathrm{mut}}$ counterparts which are far from TSS $(>100 \mathrm{~kb})$ in distal intergenic regions (Fig. 5b, c and Supplementary Fig. 5b). Assigning the 123 SATB1bound regions to the nearest gene TSS highlighted 96 genes

C

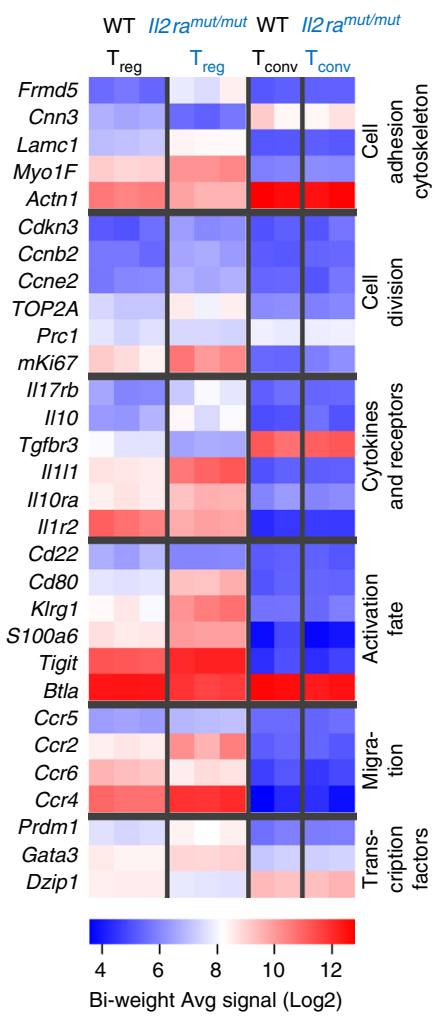

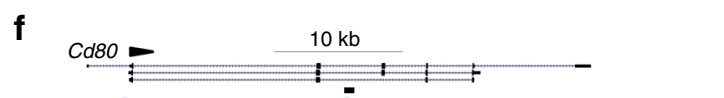

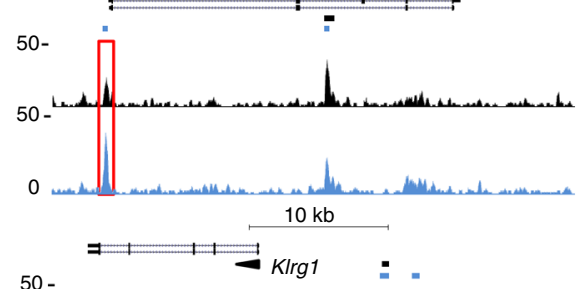

$50-$
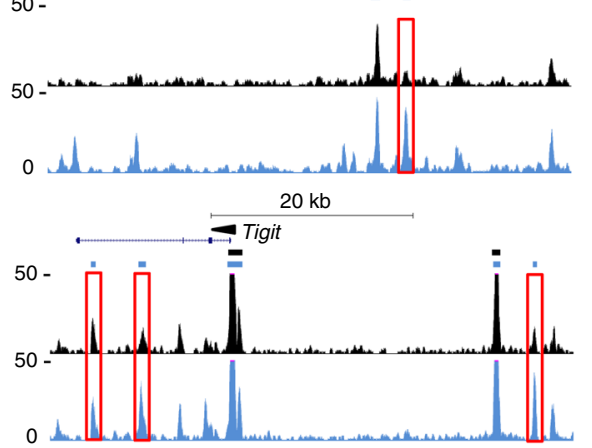

among which 26 are common to $I l 2 \mathrm{ra}^{\text {mut } / m u t} \mathrm{~T}_{\text {reg }}$ cells despite different SATB1-bound areas (Fig. 5d and Supplementary Data 7). Interestingly, 29 of the 96 genes with unique SATB1binding sites are located within less than $2 \mathrm{~kb}$ from the TSS, and a majority encodes for DNA remodeling proteins, cell cycle, signal transduction and metabolism (Supplementary Fig. 5c). These genes exhibit variable levels of expression across thymocyte development ${ }^{41}$, in particular between the SP $\mathrm{CD}^{+}$thymocyte 
Fig. 4 The expression of only a small set of genes in $T_{\text {reg }}$ cells is altered by low IL-2 signals: $\mathbf{a} 5 \times 10^{4} T_{\text {reg }}$ and $T_{\text {conv }}$ cells were sorted by flow cytometry from LNs of three independent replicate $1 / 2 \mathrm{ramut} / \mathrm{mut}$ or WT Foxp $3^{R f p} / R f p$ reporter mice and total RNA extracted and reverse transcribed to cDNA. Affymetrix mouse expression arrays (Pico 1.0) were then conducted. Principal component analysis (PCA) of expressed genes using the top 10\% of genes with the highest variance in analyzed groups with each symbol featuring one mouse. b Scatter plot of individual genes expressed in II2ramut/mut vs WT $\mathrm{T}_{\text {reg }}$ cells. Significantly upregulated and downregulated genes, defined as genes with at least 1.5 fold change, $p$-value $\leq 0.01$, are colored blue or black, respectively, and numbers are shown. c Heat map of selected genes grouped under various categories as indicated and for which expression is significantly different between $1 / 2 \mathrm{ramut} / \mathrm{mut}$ and WT $\mathrm{T}_{\text {reg }}$ cells. $\mathbf{d}$ Network analysis of biological-process gene-ontology (GO) term enrichment among significantly upregulated genes in $112 \mathrm{ra}{ }^{\text {mut} / m u t ~ v s ~ c o n t r o l ~ W T ~} \mathrm{~T}_{\text {reg }}$ cells. Upregulated genes were analyzed for over-represented GO terms using BiNGO in Cytoscape, and the resulting network was calculated and visualized using EnrichmentMap. Groups of similar GO terms were manually circled. Line thickness and color are proportional to the similarity coefficient between connected nodes. Node color is proportional to the FDR-adjusted p-value of the enrichment. Node size is proportional to gene set size. e Venn diagram comparing differentially expressed genes in II2ramut/mut vs WT $\mathrm{T}_{\text {reg }}$ cells to genes with unique peaks called in $112 \mathrm{ramut} / \mathrm{mut}$ and WT T reg cells found in ATAC-seq in Fig. 3 based on gene symbols. f ATAC-seq tracks for 3 sample genes with at least 1 unique peak localized in distinct regions of the gene (promotor, intronic, intergenic). $\mathbf{g}$ Three-way Venn diagram comparing differentially expressed genes in $/ 12$ ramut/mut versus WT $T_{\text {reg }}$ cells to genes containing unique peaks close to TSS $(<500 \mathrm{bp})$ in $/ 12 \mathrm{ra}$ mut/mut $v$ v WT $\mathrm{T}_{\text {reg }}$ cells found in ATAC-seq

and thymic $\mathrm{T}_{\text {reg }}$ cell stages, consistent with a possible regulatory role of their expression by promoter-bound SATB1. SATB1 binds $\sim 20$ times more genes (2236) in Il2 $\mathrm{ra}^{\mathrm{mut} / \mathrm{mut}}$ compared to WT thymocytes, illustrating its ectopic binding when IL-2 signals are limiting (Fig. 5d). BP-GO analysis on the common genes between the two conditions revealed that SATB1 targets common processes $(\sim 21)$ involved in DNA remodeling, transcriptional regulation and metabolism (Fig. 5e and Supplementary Fig. 5d and Data 8a,b). However, when IL-2 signaling is impaired, SATB1associated genes are implicated in 83 additional processes that include immune cell activation, adhesion and differentiation, and may reflect less focused binding. A search for known TF binding motifs within the regions bound by SATB1 highlighted GATA3, RUNX1 and ETS1 among the top ones, which are all associated with the regulation of Foxp3 expression ${ }^{15,17,42,43}$ (Fig. 5g). These motifs are AT-rich, which represent SATB1 preferential binding motifs ${ }^{44}$. While no enriched motifs are revealed in the 123 unique regions of $\mathrm{WT} \mathrm{SP} \mathrm{CD} 4^{+}$thymocytes, all of the prior ones are found in the remaining WT and Il2ramut/mut SATB1-bound regions. The proportion of these TF-binding motifs is enriched in peaks common with WT thymocytes, suggesting a more focused binding of SATB1 when normal IL-2 signals are received. Thus, IL-2 signals have a significant impact on where the pioneer factor SATB1 binds to DNA in SP CD4 ${ }^{+}$thymocytes, which is likely to contribute to IL-2 modulation of the Foxp $3^{+} \mathrm{T}_{\text {reg }}$ cell epigenetic landscape.

Il2ra ${ }^{m u t / m u t}$ mice lack autoimmunity despite altered chromatin. Given the importance of IL-2 in $\mathrm{T}_{\text {reg }}$ cell stability, immune homeostasis ${ }^{21-23,40}$ and epigenetic programming (Figs. 3, 5), we postulated that $\mathrm{Il} 2 \mathrm{ra}^{\mathrm{mut} / \mathrm{mut}}$ mice may develop symptoms consistent with autoimmunity over time. Monitoring of T cell phenotypes in the peripheral blood of Il2ramut/mut and WT mice over $\sim 1.5$ years did not reveal any differences in cell-surface expression of classical activation markers (CD44, CD62L, KLRG1), in contrast to $\mathrm{T}$ cells from Foxp $3^{y /-}$ mice analyzed 1.5 months post birth (Fig. 6a and Supplementary Fig. 6a). No T cell infiltrates were detected in the liver, pancreas or small intestine of $I l 2 \mathrm{ra}^{\text {mut/ }}$ mut mice, which all represent peripheral organs often associated with the onset of an autoimmune reaction (Fig. 6b). We next investigated how mutant $\mathrm{T}_{\text {reg }}$ cells may control autoreactive $\mathrm{T}_{\text {conv }}$ cells and maintain immune homeostasis. We first conducted an extensive characterization of $\mathrm{T}_{\text {reg }}$ cells from Il2ramut/mut compared to WT mice (Fig. 6c and Supplementary Fig. 6b). Il2 $\mathrm{ra}^{\text {mut/ }}$ ${ }^{m u t} \mathrm{~T}_{\text {reg }}$ cells express higher cell-surface levels of IL-7 and IL-15 survival receptors (CD127 and CD122) and lower levels of IL$15 \mathrm{R} \alpha$, consistent with the idea that $\mathrm{T}_{\text {reg }}$ cells receiving lower IL-2 signals may rely on the use of compensatory IL-7 and IL-15 cytokines $^{11,19,29}$. These $\mathrm{T}_{\text {reg }}$ cells also undergo increased cell proliferation $\left(\mathrm{Ki} 67^{+}\right)$and upregulated $\mathrm{T}$ cell inhibitory receptors (CTLA4, GITR) and ICOS, which are reported to promote efficient $\mathrm{T}_{\text {reg }}$ cell-mediated suppression ${ }^{45}$. We did not detect any difference in TCR V $\beta$ usage (Supplementary Fig. 6c), likely ruling out major biases in Il2ramut/mut $\mathrm{T}_{\text {reg }}$ cell repertoire. Since the common IL-2/IL-15 transducing beta chain CD122 was significantly upregulated on Il2 $\mathrm{ra}^{\mathrm{mut} / \mathrm{mut}} \mathrm{T}_{\text {reg }}$ cells compared to WT counterparts (spleen and thymus), we next crossed $\mathrm{Il} 2 \mathrm{ra}^{\mathrm{mut} / \mathrm{mut}}$ mice to $I l 15^{-/-}$mice, postulating that IL-15 signals are essential for mutant $\mathrm{T}_{\text {reg }}$ cells to maintain immune homeostasis in these mice (Fig. 6d) and compensate for impaired IL-2 signals though Il2ra $\mathrm{rut}^{\text {mut }}$ mice have higher levels of circulating IL-2 (Supplementary Fig. 6d). The proportion of activated $\mathrm{CD}^{+}$

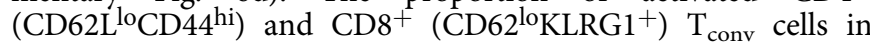

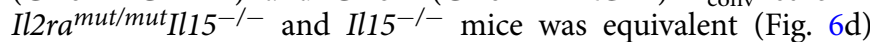
and similar to that of WT mice (Fig. 6a), but significantly lower than in Foxp $3^{y /-}$ mice. In addition, we did not find any evidence of $\mathrm{T}$ cell infiltrates in the liver or the spleen of these mice (Supplementary Fig. 6e). However, the proportion of Foxp $3^{+} \mathrm{T}_{\text {reg }}$ cells in Il2ramut/mut $I l 15^{-1-}$ mice was reduced compared to WT, Il2 $\mathrm{ra}^{\mathrm{mut} / \mathrm{mut}}$ or $\mathrm{Il15^{-/ } -}$ mice (Fig. 6e). Recently, two distinct subsets of $\mathrm{T}_{\text {reg }}$ cells discriminated on CD44, CD62L and CCR7 expression were proposed to require either IL-2 (CD44 $\left.{ }^{\text {lo }} \mathrm{CD} 62^{\mathrm{hi}}\right)$ or ICOS (CD44 ${ }^{\text {hi }} \mathrm{CD} 62^{\mathrm{lo}}$ ) signaling for their maintenance ${ }^{46}$. Since we noted high cell-surface expression of ICOS on Il2ramut/mut $\mathrm{T}_{\text {reg }}$ cells (Fig. $6 \mathrm{c}$ ), we reasoned that impaired IL-2 signals might favor the onset of a CD44 ${ }^{\text {hi }} \mathrm{CD} 62^{\text {lo }} \mathrm{T}_{\text {reg }}$ cell subset that requires ICOS signaling. Unexpectedly, we only observed lower proportions of the CD44hiCD62 ${ }^{\text {lo }} \mathrm{T}_{\text {reg }}$ cell subset in Il2 $\mathrm{ra}^{\mathrm{mut} / \mathrm{mut}}$ and Il2 $\mathrm{ra}^{\mathrm{mut} / \mathrm{mut}} \mathrm{Il15^{-1 } -}$ compared to WT mice, and this proportion was even further decreased by blocking ICOS for 2 weeks (Fig. 6f). The overall proportion of Foxp $3^{+} \mathrm{T}_{\text {reg }}$ cells among CD4 $+\mathrm{T}$ cells in the blood of ICOS-neutralized Il $2 \mathrm{ramt}^{\mathrm{mu} / \mathrm{mut}} \mathrm{Il}_{15} \mathrm{5}^{-1-}$ mice was also reduced by $\sim 50 \%$, although mice did not develop autoimmunity (Fig. 6e and Supplementary Fig. 6f), suggesting that none of the proposed mechanisms accounts for the absence of autoimmune disease in $\mathrm{Il} 2 \mathrm{ra}^{\mathrm{mut} / \mathrm{mut}}$ mice.

Il2ra ${ }^{m u t / m u t} \mathrm{~T}_{\text {reg }}$ cells cannot repress $\mathrm{WT}$ autoimmune $\mathrm{T}$ cells. Lack of IL-2 or its receptor chains leads to fatal autoimmunity because $\mathrm{T}_{\text {reg }}$ cells are unstable and fail to suppress autoreactive $\mathrm{T}_{\text {conv }}$ cells ${ }^{1 P-13}$. Yet, mice in which IL-2 signaling is genetically altered by targeted mutation in the IL-2R $\beta / C D 122$ transducing chain do not become autoimmune ${ }^{29}$. Thus, we reasoned that similar to IL-2R $\beta$ mutant $\mathrm{T}_{\text {reg }}$ cells, Il $2 \mathrm{ra}^{\mathrm{mut} / \mathrm{mut}} \mathrm{T}_{\text {reg }}$ cells may repress $I l 2 \mathrm{ra}^{\text {mut } / \mathrm{mut}}$ but not WT autoreactive $\mathrm{T}_{\text {conv }}$ cells. As a first step to assess this idea, we conducted a standard in vitro suppression assay using increasing numbers of $\mathrm{Il} 2 \mathrm{ra}^{\mathrm{mut} / \mathrm{mut}}$ or control WT $\mathrm{T}_{\text {reg }}$ cells incubated with CFSE-labeled anti-CD3 activated $\mathrm{T}_{\text {conv }}$ cells (Supplementary Fig. 7a). Il2ramut/mut $\mathrm{T}_{\text {reg }}$ cells inhibit $\mathrm{T}_{\text {conv }}$ cell proliferation $\sim$ two fold less than $\mathrm{WT}_{\mathrm{T}} \mathrm{T}_{\text {reg }}$ cells across all ratios, possibly accounting for the lack of autoimmunity in $I l 2 \mathrm{ra}^{\mathrm{mut} / \mathrm{mut}}$ mice. Since $\mathrm{T}_{\text {reg }}$ cells grown in vitro 
a

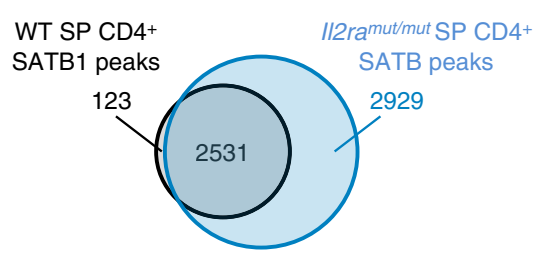

b

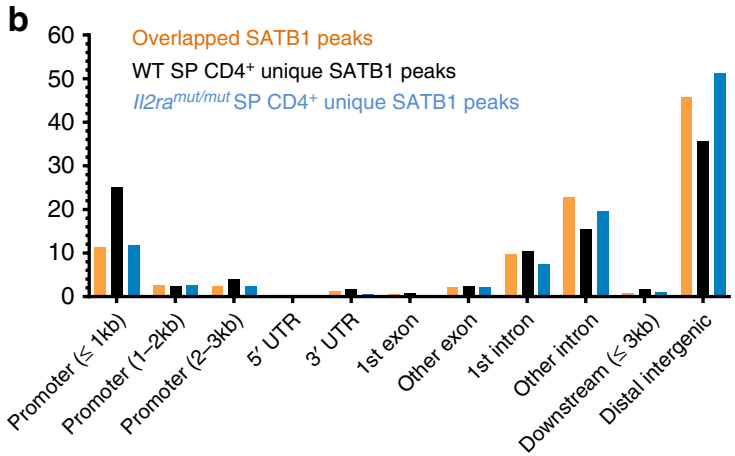

d

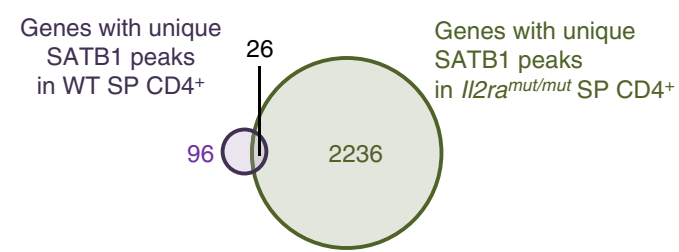

f

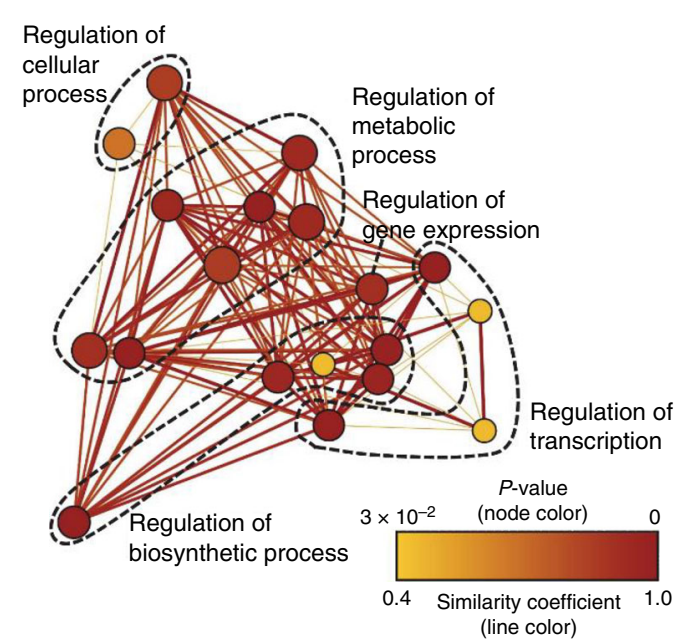

e BP-GO terms from genes with unique peaks in WT CD4 $4^{+} \mathrm{SP}$

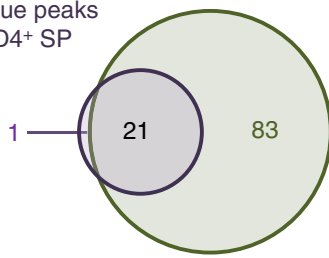

g

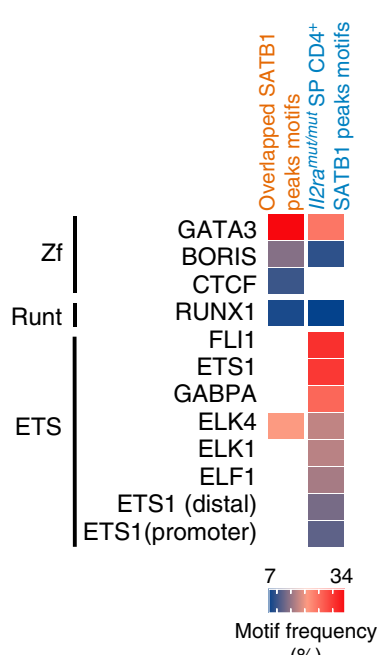

(\%)
BP-GO terms from genes with unique SATB1 peaks in $112 \mathrm{ra}^{\text {mut }}{ }^{\text {mut }} \mathrm{CD}^{+} \mathrm{SP}$
$1-3 \mathrm{~kb}$

$3-5 \mathrm{~kb}$

5-10 kb

10-100 kb

$>100 \mathrm{~kb}$

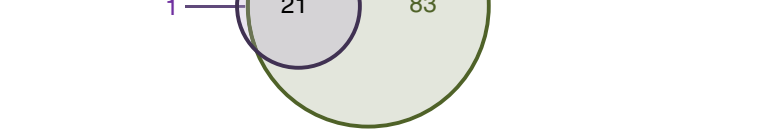

Fig. 5 Ectopic DNA binding of SATB1 in SP CD4 $4^{+}$thymocytes receiving low IL-2 signals: $2 \times 10^{6}$ SP CD4 $4^{+}$thymocytes were sorted in 2 independent duplicate experiments by flow cytometry from the thymus of $112 \mathrm{ramut} / \mathrm{mut}$ and WT mice, PFA fixed, lysed, and cross-linked DNA was used for chromatin immunoprecipitation sequencing (ChIP-seq) of the pioneer factor SATB1. a Venn diagram of the number of common and unique SATB1 DNA binding peaks in $1 / 2 \mathrm{ramut}^{\mathrm{m}}$ mut vs WT SP CD4+ thymocytes. $\mathbf{b}$, $\mathbf{c}$ Distribution of common and unique SATB1 DNA binding peaks across gene organization (b) and distance to the transcription start site (TSS, $\mathbf{c}$ ) in the whole genome. $\mathbf{d}$ Venn diagram of the number of genes exhibiting unique SATB1 DNA binding peaks in $1 / 2 \mathrm{ramu}^{\text {mut }}$ ut vs WT SP CD4+ thymocytes. e Venn diagram of biological-process gene-ontology (BP-GO) from genes with unique SATB1 DNA binding peaks in WT vs $\| 2 \mathrm{ramut} /$ mut SP CD4+ thymocytes. $\mathbf{f}$ Network analysis of BP-GO term enrichment among genes with unique SATB1 DNA binding peaks in WT SP CD4 ${ }^{+}$thymocytes. Genes with unique SATB1-binding peaks were analyzed for over-represented GO terms using BiNGO in Cytoskape, and the resulting network was calculated and visualized using EnrichmentMap in Cytoscape. Groups of similar GO terms were manually circled. Line thickness and color are proportional to the similarity coefficient between connected nodes. Node color is proportional to the FDR-adjusted $p$-value of the enrichment. Node size is proportional to gene set size. $\mathbf{g}$ Frequency of known TF binding site motifs enriched in common and unique SATB1 DNA binding peaks in WT and $112 \mathrm{ra}^{\mathrm{mut} / \mathrm{mut}} \mathrm{SP}$ CD4 ${ }^{+}$thymocytes. Motif frequency (\%) is shown in heat map 
a

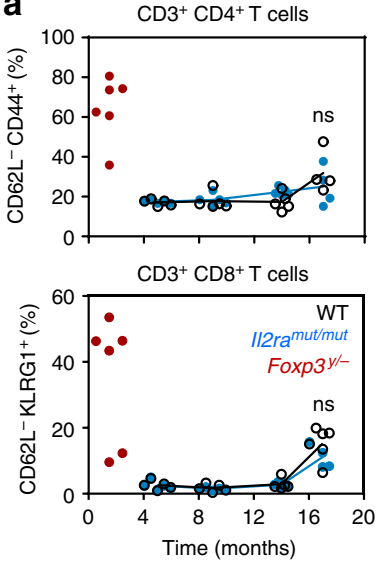

b

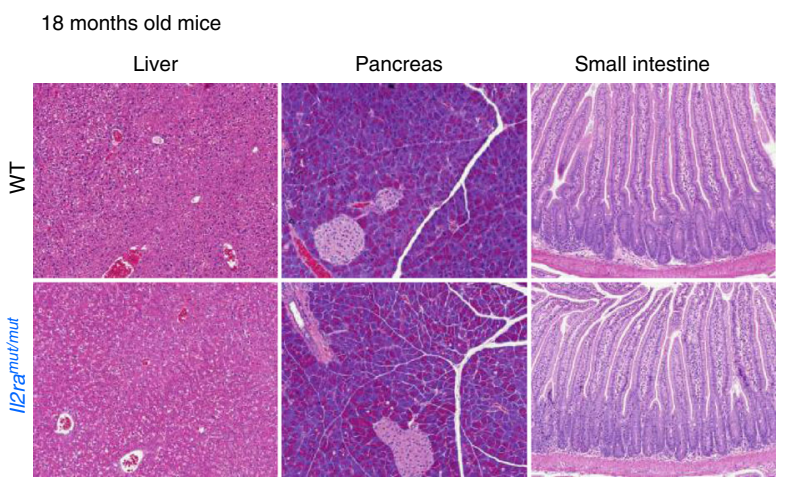

C Gated on $\mathrm{CD}^{+} \mathrm{CD}^{+}{ }^{+} \mathrm{Foxp}^{+}$cells (spleen) CD25-PE-Cy7 CD122-FITC IL-15R $\alpha$-PE IL-7R $\alpha$-APC FOXP3-Pac.blue CD3-BV510

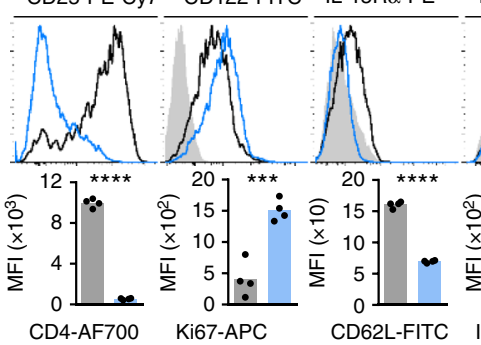

IL-7R $\alpha$-APC FOXP3-Pac.blue CD3-BV510

d

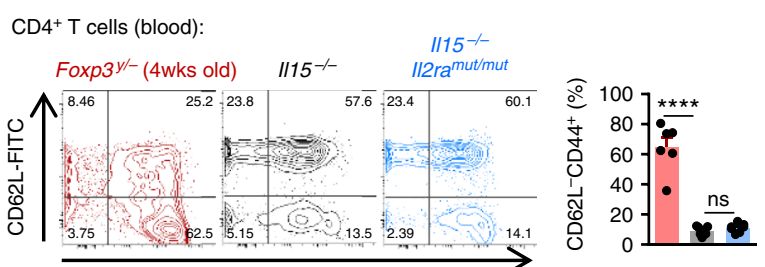

CD8 ${ }^{+} \mathrm{T}$ cells (blood):
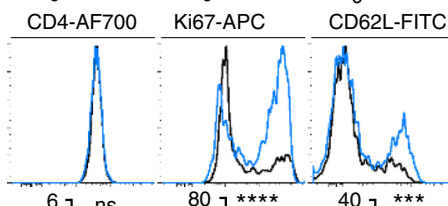

01

0
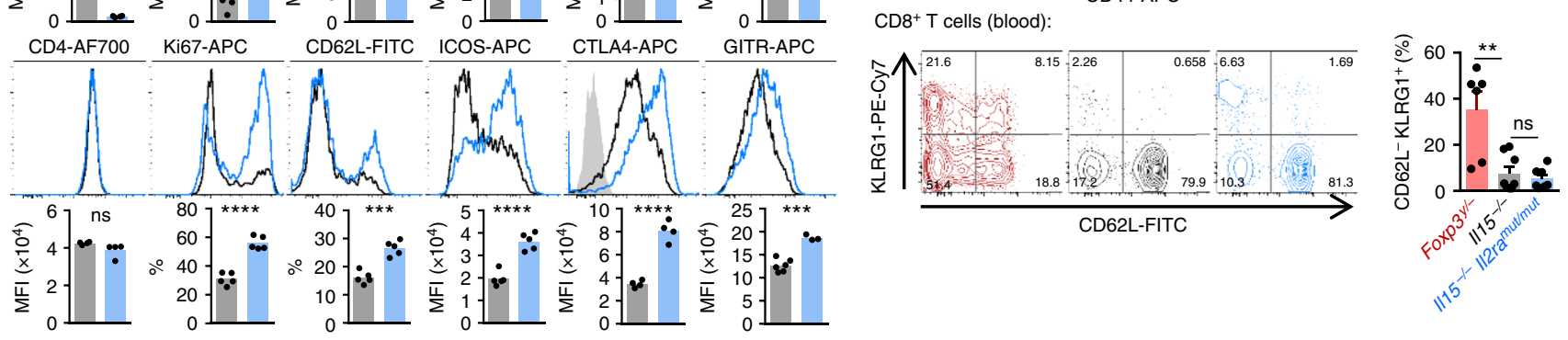

$\mathbf{e}$ WT II2ramut/mut FMO control

f
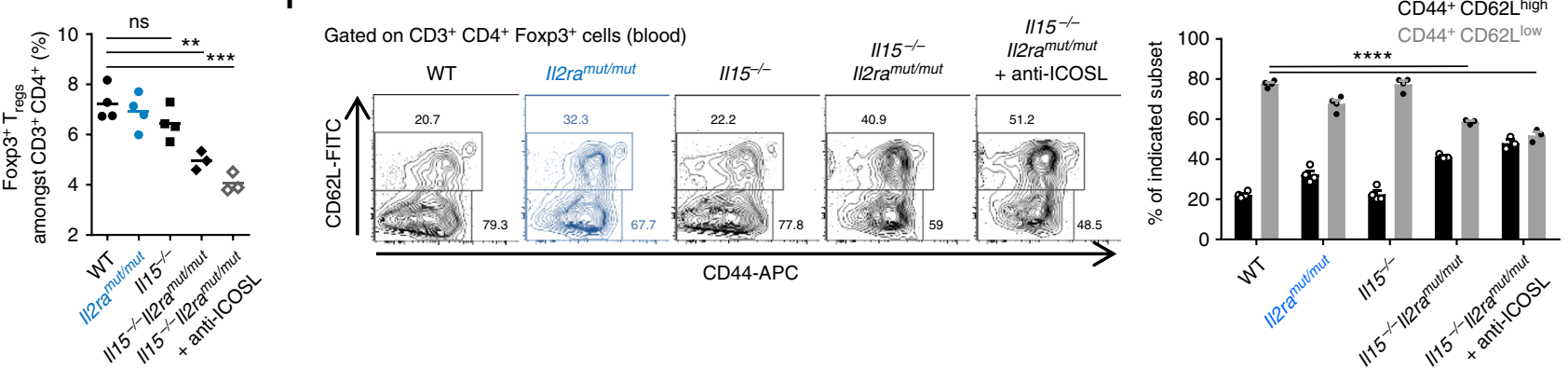

Fig. 6 //2ramut/mut mice do not develop any signs of autoimmunity: a T cells collected from blood of $/ 12 \mathrm{ramut} / \mathrm{mut}$ and WT mice were stained for cell-surface CD3, CD8, CD4 and CD62L, CD44, KLRG1 activation markers at indicated times over an 18 months period. Blood from control Foxp3y/- was analyzed at 1.5 months post birth. Each symbol represents an individual mouse. b At month 18, liver, pancreas, and small intestine were harvested, fixed/cut, and stained with H/E. c Spleen cells from 8 to 10-weeks-old I/2ramut/mut and WT mice were stained for cell-surface CD3, CD4, intracellular Foxp3 and indicated markers. Overlay of representative FACS histograms after gating on $\mathrm{CD} 3^{+} \mathrm{CD} 4^{+}$Foxp3 ${ }^{+} \mathrm{T}$ cells are shown and bar graphs average relative expression levels (MFI, $n=4-5)$. d Blood from $/ 12 \mathrm{ramut} /$ mut $/ 115^{-/-}, 1175^{-/-}$(6 months old) or Foxp3y/- mice was stained as in a and representative FACS dot plots with bar graphs summarizing average across mice $(n=6-7)$ are shown. e Proportion of peripheral blood Foxp3 ${ }^{+} \mathrm{T}_{\text {reg }}$ cells among $\mathrm{CD} 3^{+} \mathrm{CD} 4^{+} \mathrm{T}$ cells in indicated mice treated (or not) with anti-ICOSL for 2 weeks. $\mathbf{f}$ Blood leukocytes from indicated mice groups were stained for expression of CD3, CD4, intracellular Foxp3, CD62L, CD44. Representative dot plots and summary bar graphs of average CD44/CD62L expression levels across all groups of mice are shown $(n=3-4)$. $p$-values are indicated when relevant with ${ }^{\star} p<0.05 ;{ }^{\star \star} p<0.01$; ${ }^{\star \star \star} p<0.001$; NS not significant, using two-tailed unpaired Student's t-test 
a
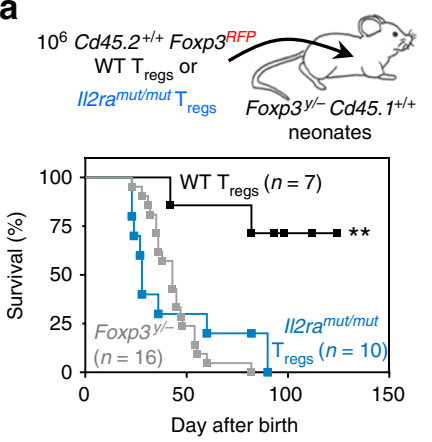

b

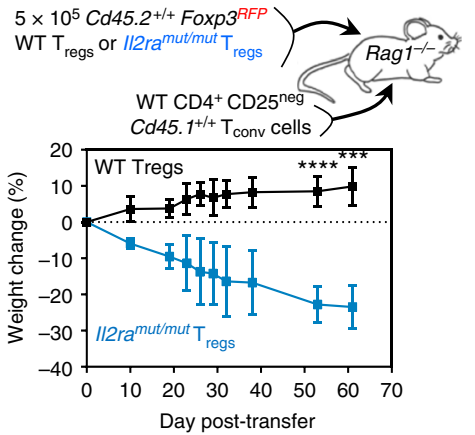

C

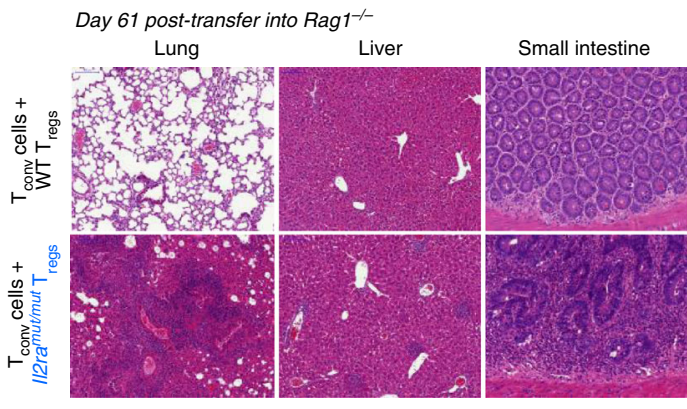

d Day 61 post-transfer into Rag 1//-

e Day 45 post-transfer into Rag 1/--

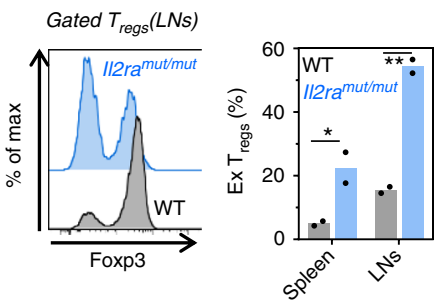

Day 75 post-transfer into Rag $1^{-/-}$

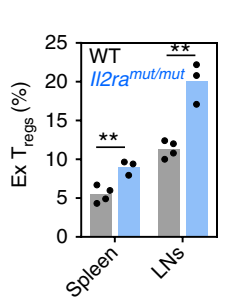

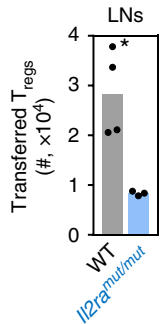

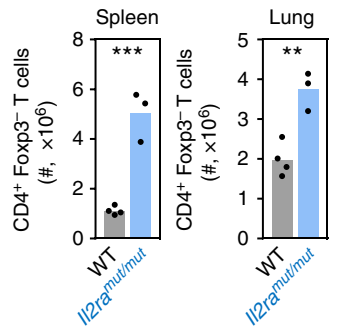

$\mathbf{f}$

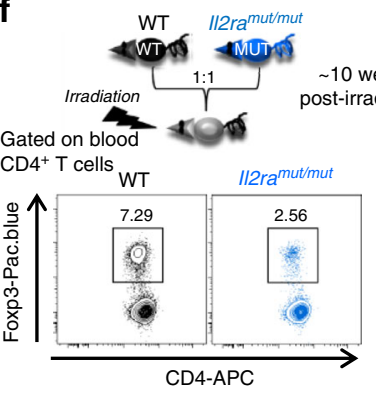

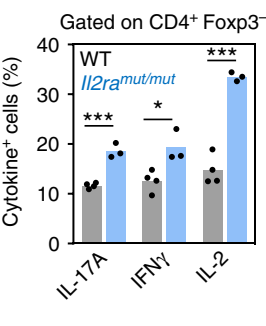

g

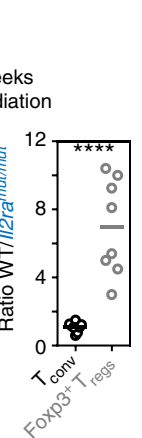

i $\sim 6$ weeks post-irradiation

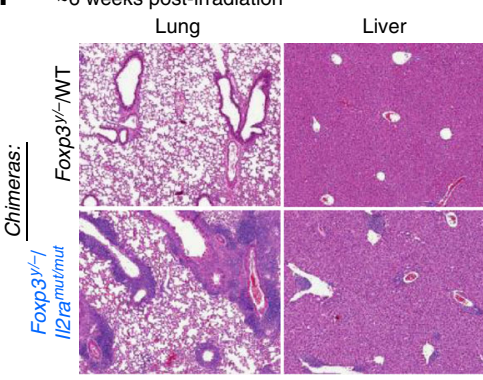

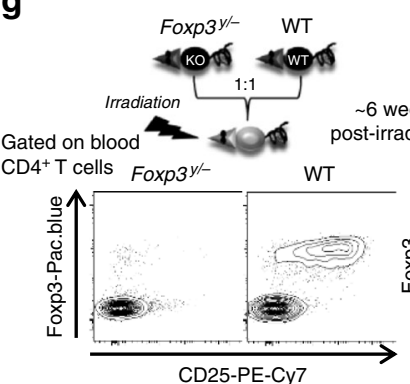

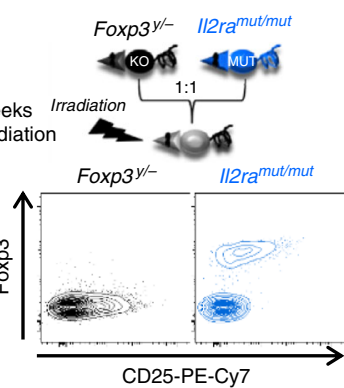

h

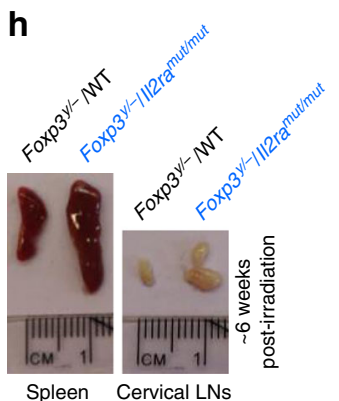

j $\sim 6$ weeks post-irradiation Chimeras:

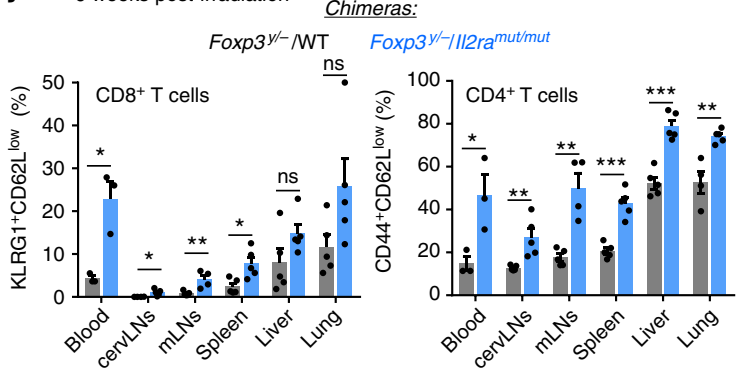

$\mathbf{k}$

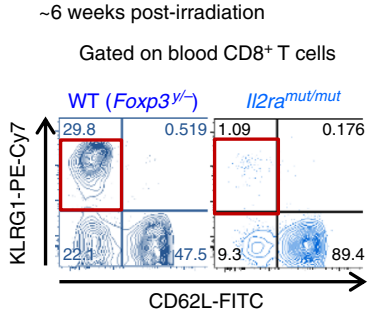

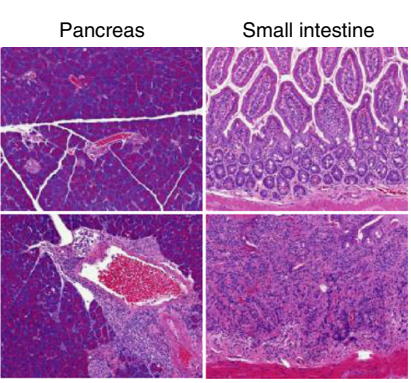

Chimeras:

Foxp3y/-/II2ramutm

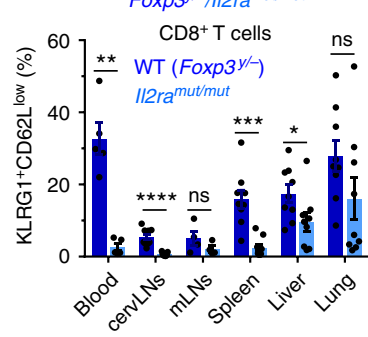

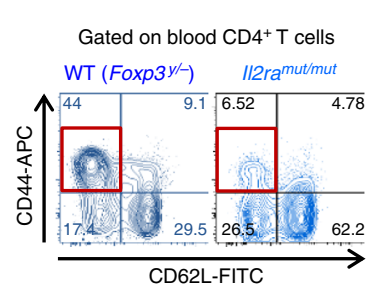

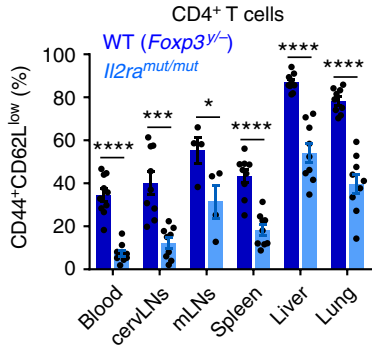

with anti-CD3/CD28 stimulation and under limited IL-2 availability lose Foxp3 expression and convert to effector $\mathrm{T}$ cells ${ }^{18}$, we next assessed whether Il2ramut/mut $\mathrm{T}_{\text {reg }}$ cells also lacked stability after TCR triggering in vitro (Supplementary Fig. 7b). While $\sim 60 \%$ of WT $\mathrm{T}_{\text {reg }}$ cells lost Foxp3 expression, $\sim 85 \%$ of
Il2ramut/mut converted to Foxp3 $3^{\text {neg }} \mathrm{T}$ cells, consistent with impaired lineage stability when IL-2 signals are limiting. Thus, even if they can prevent autoimmunity in Il2ra ${ }^{m u t / m u t}$ mice, Il2ramut/mut $\mathrm{T}_{\text {reg }}$ cells may not be able to suppress WT autoreactive $\mathrm{T}_{\text {conv }}$ cells to the extent to which $\mathrm{WT} \mathrm{T}_{\text {reg }}$ cells can. 
Fig. $7 \mathrm{~T}_{\text {reg }}$ cells receiving limited IL-2 signals cannot suppress autoreactive WT $\mathrm{T}_{\text {conv }}$ cells: a Foxp3y/- Cd45. $1^{+/+}$neonate mice were transferred i.p. with $10^{6} / 12 \mathrm{ra}^{\text {mut/mut }}$ or WT flow-purified Foxp3 ${ }^{R f p} / R f p ~ C D 3^{+} \mathrm{CD} 4^{+} \mathrm{T}_{\text {reg }}$ cells and survival was monitored over 120 days. Graphs average results over multiple mice in each group and 7-16 replicate experiments. b, c Rag $1^{-1-}$ mice received $5 \times 10^{5}$ flow-purified Foxp $3^{R f p} / R f p\left(D 3^{+} \mathrm{CD} 4+\mathrm{T}_{\text {reg }}\right.$ cells together with $1.5 \times 10^{6}$ WT CD3 $+C D 4+C D 25^{\text {neg }} \mathrm{T}_{\text {conv }}$ cells i.v. Weight loss was monitored up to 61 days post transfer and immune cell infiltrates on $\mathrm{H} / \mathrm{E}$ stained sections is shown at day $61(n=4)$. d Numbers of transferred Foxp3 $3^{R f p / R f p} \mathrm{CD} 3^{+} \mathrm{CD} 4^{+} \mathrm{T}_{\text {reg }}$ cells in the spleen and lung of Rag1 ${ }^{-/-}$mice (left bar graphs) and proportion of cytokine-secreting $\mathrm{CD} 3+\mathrm{CD} 4+\mathrm{T}_{\text {conv }}$ cells $4 \mathrm{~h}$ post $\mathrm{PMA}$ /ionomycin stimulation. e Foxp3 expression in Foxp3 ${ }^{R f p / R f p} \mathrm{CD} 3+\mathrm{CD} 4{ }^{+} \mathrm{T}_{\text {reg }}$ cells 45 and 75 days post transfer, proportion and absolute numbers of ex- $T_{\text {reg }}$ cells in LNs and spleens. $\mathbf{f}, \mathbf{g}$ Schematic of mixed bone-marrow chimera generation in lethally irradiated WT B6 recipient mice with discriminative congenic markers. $\mathbf{f}$, $\mathbf{g}$ Representative FACS dot plots of Foxp3 and CD4 expression in blood T cells of $\mathbf{f}$ WT/II2ramut/mut and $\mathbf{g}$ Foxp3y/-/WT and Foxp3y/-/II2ra mut/mut chimeras 10 and 6 weeks post reconstitution, respectively. Graph in $\mathbf{f}$ shows the ratio of WT vs $1 / 2 \mathrm{ramut} / \mathrm{mut} \mathrm{T}_{\text {conv }}$ and $\mathrm{T}_{\text {reg }}$ cells for each individual chimera. Data are across several chimeras (5-9 mice/ group) in 3-4 replicate experiments. h, i Spleen, LN pictures, and H/E stained sections of lung, liver, pancreas, and small intestine from Foxp3y/- /WT and Foxp3 $\mathrm{Y}^{\mathrm{V}-}-/ 112 \mathrm{ra}$ mut/mut chimeras. $\mathbf{j}$ Cells from indicated organs from the two groups of chimeras were stained for cell-surface expression of CD3, CD4, CD8, CD62L, KLRG1, and CD44. Bar graphs show the proportion of activated CD4+ $\left(\mathrm{CD} 44+{ }^{+} \mathrm{CD} 62 \mathrm{~L}^{\mathrm{lo}}\right)$ or $\mathrm{CD} 8+\left(\mathrm{KLRG1} 1^{+} \mathrm{CD} 62 \mathrm{~L}^{\mathrm{lo}}\right) \mathrm{T}$ cells $(n=5-9)$. k Proportion of activated $\mathrm{CD}^{+} \mathrm{CD}^{+}$or $\mathrm{CD} 8^{+} \mathrm{T}_{\text {conv }}$ cells from $1 / 2 \mathrm{ra}{ }^{\text {mut} / m u t}$ or WT BM in Foxp $3^{\mathrm{y} /-} / 112 \mathrm{ramut} / \mathrm{mut}$ chimeras. Bar graphs summarize average proportion across mice $(n=5-9)$. p-values are indicated when relevant with ${ }^{\star} p<0.05 ;{ }^{\star \star} p<0.01 ;{ }^{\star \star \star} p<0.001$; NS not significant, using two-tailed unpaired Student's t-test. Symbols on bar graphs feature individual mice

To further evaluate their suppressive capacity in vivo, we used two distinct but complementary models of acute autoimmunity development, and a model of reconstitution at homeostasis. We first conducted rescue experiments of Foxp $3^{y /-}$ mice ${ }^{5}$ which develop fatal autoimmunity within $\sim 3-4$ weeks post birth, by transferring $\mathrm{T}_{\text {reg }}$ cells sorted from the secondary lymphoid organs (SLOs) of WT or Il2ramut/mut Foxp $3^{R f p / R f p}$ reporter mice to recipient neonates (day 1-3) (Fig. 7a). As expected, Foxp $3^{y /-}$ mice receiving $\mathrm{WT} \mathrm{T}_{\text {reg }}$ cells survived, while those transferred with Il $2 \mathrm{ra}^{\mathrm{mut} / \mathrm{mut}} \mathrm{T}_{\text {reg }}$ cells did not control the development of wasting disease and ultimately succumbed, as did untransferred counterparts. Second, we adoptively transferred $\mathrm{CD} 4{ }^{+} \mathrm{CD} 25^{\text {neg }}$ $\mathrm{T}_{\text {conv }}$ cells to Rag1 $^{-/}$mice, which also results in a rapid wasting disease unless functional $\mathrm{T}_{\text {reg }}$ cells are co-transferred (Fig. $7 \mathrm{~b}$ ). As predicted from the first model, Il $2 \mathrm{ra}^{\mathrm{mut} / \mathrm{mut}} \mathrm{T}_{\text {reg }}$ cells fail to suppress autoreactive $\mathrm{T}_{\text {conv }}$ cell-mediated autoimmunity with a rapid loss of weight and massive infiltrates of $\mathrm{T}$ cells in multiple organs (lung, liver, small intestine) in contrast to control groups transferred with WT $\mathrm{T}_{\text {reg }}$ cells or only $\mathrm{CD}^{+} \mathrm{T}_{\text {conv }}$ cells (Fig. 7c and Supplementary Fig. 7c). Consequently, the absolute numbers of $\mathrm{CD} 4^{+} \mathrm{T}_{\text {conv }}$ cells were two (lung) to five (spleen) fold increased in autoimmune mice with a higher proportion secreting IL-2 (factor of 2), IL-17A, and IFN $\gamma$ (Fig. 7d). Fate mapping of Il2 $\mathrm{ra}^{\text {mut } / m u t}$ or WT $\mathrm{T}_{\text {reg }}$ cells transferred to Rag1-/- (Fig. 7e) or Foxp $3^{y /-}$ (Supplementary Fig. 7d) mice further showed that Foxp $^{+}$Il2ra ${ }^{\text {mut } / m u t} \mathrm{~T}_{\text {reg }}$ cells become ex- $\mathrm{T}_{\text {reg }}$ cells and are lost compared to WT counterparts, both in proportion and absolute numbers. Thus, a threshold of IL-2 signals to $\mathrm{T}_{\text {reg }}$ cells is needed to program their functional attributes, for their maintenance, and to prevent wasting autoimmunity. Consistent with this conclusion and the lack of competitive fitness ${ }^{21}$ of $I l 2 \mathrm{ra}^{m u t} / \mathrm{mut} \mathrm{T}_{\text {reg }}$ cells, a significantly lower proportion of Il2 $\mathrm{ra}^{\mathrm{mut} / \mathrm{mut}}$ compared to WT $\mathrm{T}_{\text {reg }}$ cells was measured in WT B6 chimeric mice reconstituted with an equal ratio of $I l 2 \mathrm{ra}^{\mathrm{mut} / \mathrm{mut}}$ and WT bone-marrow donor cells while the proportion of $\mathrm{CD} 4^{+} \mathrm{T}_{\text {conv }}$ cells was maintained (Fig. 7f).

As a last step to assess Il2 $\mathrm{ra}^{\mathrm{mut} / \mathrm{mut}} \mathrm{T}_{\text {reg }}$ cells functional attributes, we created another chimeric mouse model at homeostasis in which $\mathrm{T}_{\text {reg }}$ cells lacked full IL-2 responsiveness while $\mathrm{T}_{\text {conv }}$ cells responded normally. We reconstituted lethally irradiated WT mice with bone marrow cells from Foxp $3^{y /-}$ and Il $2 \mathrm{ra}^{\text {mut } / m u t}$ or control WT mice (Fig. $7 \mathrm{~g}$ ). In such Foxp $3^{y /-} /$ Il2 $\mathrm{ra}^{\text {mut } / \mathrm{mut}}$ chimeras, only $\mathrm{T}_{\text {reg }}$ cells lacked CD25 expression and mice exhibited enlarged spleens and LNs compared to the Foxp $3^{y /-} / \mathrm{WT}$ control chimeras (Fig. 7h). Moreover, massive infiltrates of $\mathrm{T}$ cells were noted in lung, liver, pancreas and small intestine of Foxp $3^{y /-} / I l 2 \mathrm{ra}^{m u t / m u t}$ mice, with gross architectural tissue alterations compared to the control group (Fig. 7i). In line with these findings, both $\mathrm{CD}^{+}$and $\mathrm{CD}^{+} \mathrm{T}$ cells in Foxp $3^{y /-} /$ Il2 $\mathrm{ra}^{\text {mut } / \text { mut }}$ but not Foxp $3^{y /-} / \mathrm{WT}$ chimeras underwent robust activation (CD62 $\mathrm{L}^{\text {low }}, \mathrm{KLRG}^{+}{ }^{+}, \mathrm{CD} 44^{\mathrm{hi}}, \mathrm{CD} 69^{\mathrm{hi}}$ ) across multiple tissues (Fig. 7j and Supplementary Fig. 7e, f). Only WT but not Il2ra mut $/$ mut $\mathrm{T}_{\text {conv }}$ cells in Foxp3 $3^{y /-} /$ Il $2 \mathrm{ra}^{\text {mut } / m u t}$ chimeras were activated (Fig. $7 \mathrm{k}$ and Supplementary Fig. $7 \mathrm{~g}$ ), suggesting that equal responsiveness to IL- 2 by $\mathrm{T}_{\text {conv }}$ cells and $\mathrm{T}_{\text {reg }}$ cells represent a major parameter safeguarding immune homeostasis. In summary, $\mathrm{T}_{\text {reg }}$ cells that can only integrate lower IL-2 signals than their $\mathrm{T}_{\text {conv }}$ cell counterpart, acquire a suboptimal epigenetic program, are less stable (Foxp3) and are impaired in their ability to deprive autoreactive $\mathrm{T}_{\text {conv }}$ cells of IL-2.

\section{Discussion}

While the Foxp3 TF is required to maintain peripheral $\mathrm{T}_{\text {reg }}$ cell identity and functions, it is not sufficient to secure their stable epigenetic identity and program their functional features $12,16,24$ But how exactly are $\mathrm{T}_{\text {reg }}$ cell chromatin accessibility characteristics determined before Foxp3 is expressed is still hotly debated. TCR signaling represents the major cue driving thymic selection, and this plays a determining role in thymocytes commitment to the $\mathrm{T}_{\text {reg }}$ cell lineage ${ }^{47}$, however this is likely not sufficient ${ }^{12,14,25}$. Signals such as IL- 2 and TGF $\beta$ cytokines, are suggested to contribute to the epigenetic modeling of $\mathrm{T}_{\text {reg }}$ cells ${ }^{2,3}$, yet current evidence for IL-2 mostly pointed to its role as a major stabilizer of Foxp3 expression. Here, our data support a role for IL-2 in defining the epigenetic identity of Foxp $3^{+} \mathrm{T}_{\text {reg }}$ cells, which appears largely independent of Foxp3. In fact, genome-wide chromatin accessibility changes when IL-2 signals are impaired are much wider than the regions where Foxp3 binds. Our whole genome analysis of OCRs in Il2ramut/mut vs WT $\mathrm{T}_{\text {reg }}$ cells from the LNs reveals that the epigenetic landscapes are widely distinct $(\sim 41 \%)$. Consistent with this result, constitutive STAT5 expression, which forces IL-2 signaling, is shown to divert thymocyte selection to the $\mathrm{T}_{\text {reg }}$ cell lineage ${ }^{1 \mathrm{P}}$. Using data from a prior report on $\mathrm{T}_{\text {reg }}$ cell epigenetic signature under various conditions of activation $^{36}$, we analyzed that $\sim 36 \%$ of OCRs differed in activated vs resting Foxp $3^{+} \mathrm{T}_{\text {reg }}$ cells, a proportion comparable to the extent of IL-2-mediated remodeling observed in WT vs IL2 $\mathrm{ra}^{\text {mut/mut }} \mathrm{LN} \mathrm{T}_{\text {reg }}$ cells. These differences are equivalent to what is documented between effector and memory or exhausted $\mathrm{CD}^{+} \mathrm{T}$ cells ${ }^{38}$, which are undergoing extensive chromatin remodeling upon differentiation ${ }^{37-39}$, overall supporting the conclusion that IL-2 signals significantly shape the epigenetic landscape of $\mathrm{T}_{\text {reg }}$ cells in vivo. 
Because IL-2 signals mediate genome-wide chromatin remodeling beyond Foxp3, and already on mature Foxp $3^{+} \mathrm{T}_{\text {reg }}$ cells in the thymus, we postulated that this may occur in the thymus at the SP $\mathrm{CD}^{+}$thymocyte stage preceding Foxp3 expression in committed $\mathrm{T}_{\text {reg }}$ cells. The genome organizer SATB1, which is highly expressed during most stages of $\mathrm{T}$ cell thymic selection, was recently involved in setting-up thymic-derived $\mathrm{T}_{\text {reg }}$ cell functional features and ability to prevent autoimmunity before Foxp3 is turned on ${ }^{27}$. We further reveal that SATB1 positioning in the genome of SP $\mathrm{CD}^{+}$thymocytes impaired in IL-2 signaling, is much broader than in WT thymocytes, likely reflecting ectopic binding of this pioneer factor when IL-2 signals are limiting. Our finding that more than 20 times as many GO pathways are associated with the genes exhibiting unique OCRs in WT LN $\mathrm{T}_{\text {reg }}$ cells compared to IL2ramut/mut counterparts supports the idea that such ectopic binding of SATB1 lead to unfocused $\mathrm{T}_{\text {reg }}$ cell chromatin modeling. In WT thymocytes, SATB1 is more selectively bound to the TSS of genes encoding for TFs and nucleic acid binding proteins, which may in turn control the correct $\mathrm{T}_{\text {reg }}$ cell epigenetic landscape. Several TFs such as STAT5 and PI3/MAP kinase-dependent TFs, are activated downstream of IL-2 signaling. From our analysis of the SATB1 DNA binding regions and TFs known to bind to these motifs, we noted GATA3, RUNX1 and ELF1 that are all reported to be present prior to Foxp3 expression to enable its future recruitment and optimal function ${ }^{15,17,26,43}$. SATB1 is also described among the "quintet" TFs - together with Foxp3-that are essential for in vitro re-programing of $\mathrm{T}_{\text {conv }}$ cells to $\mathrm{T}_{\text {reg }}$ cells ${ }^{16}$. While still speculative, it is possible that IL-2 signals, in addition to TCR triggering, are essential to promote the expression/activation of the previous TFs and of SATB1 and/or other pioneer factors, to set-up the appropriate epigenetic landscape on which Foxp3 and these partner TFs act to achieve the final $\mathrm{T}_{\text {reg }}$ cell identity. Binding to the Foxp3 CNS3 and CNS2 elements for instance is essential to initiate and then stabilize expression of Foxp3 $3^{17,18,26,48}$. The NF-kB subunit c-Rel binds CNS3, and STAT5 and GATA3 ${ }^{49}$ stabilize CNS2. While we did not find evidence for SATB1-binding on c-Rel or STAT5 motifs, SATB1 may associate with GATA3 to help focus its binding to DNA area relevant to the acquisition of the $T_{\text {reg }}$ cell signature prior Foxp 3 is expressed. Such mechanism would prevent ectopic binding of SATB1 throughout the genome when IL-2 signals are limiting.

The consequence of lower IL-2 signaling in thymic-derived peripheral $\mathrm{T}_{\text {reg }}$ cells is a different epigenetic landscape, which we suggest is being set in the thymus through SATB1 together with other IL-2-dependent TFs. In the periphery, however, SATB1 is not required to sustain functional thymic-derived $\mathrm{T}_{\text {reg }}$ cells ${ }^{27}$. Some TF binding motifs found in SATB1-binding regions like RUNX1, which is likely to interact with SATB1 in SP CD4 ${ }^{+}$ thymocytes, are also among the motifs found in the differential OCRs of WT compared to Il2ramut/mut $\mathrm{T}_{\text {reg }}$ cells in the periphery. RUNX1 binds to the IL-2 promoter and promotes its transcription, but is repressed by Foxp3 through physical interactions ${ }^{42}$, preventing the expression of an effector $\mathrm{T}$ cell program by $\mathrm{T}_{\text {reg }}$ cells. Other TF binding motifs only found in WT peripheral $\mathrm{T}_{\text {reg }}$ cells, such as FOXO1 and FOXO3, also bind to the Foxp3 promoter and conserved intronic enhancer regions, allowing for Foxp3 expression and $\mathrm{T}_{\text {reg }}$ cell-lineage specification ${ }^{50}$. IL-2mediated induction of all these TFs at the pre- $\mathrm{T}_{\text {reg }}$ cell stage, via SATB1 or not, may help maintain the $\mathrm{T}_{\text {reg }}$ cell program in the periphery. Along these lines, we noted multiple differentially expressed TF-encoding genes (Prdm1, Gata3, Dzip1, Irf4), chromatin remodeling- and histone-encoding genes between WT and Il2 $\mathrm{ra}^{\text {mut } / \text { mut }} \mathrm{LN} \mathrm{T}_{\text {reg }}$ cells.

Given that our data support a model in which IL-2 alters $\mathrm{T}_{\text {reg }}$ cell epigenetic identity early during thymic selection when thymocytes commit to this lineage, it is unlikely that this mechanism will be at work for induced $\mathrm{T}_{\text {reg }}$ cells in peripheral tissues ${ }^{51}$. Our analysis in WT vs $I l 2 \mathrm{ra}^{\text {mut/mut }} \mathrm{T}_{\text {reg }}$ cells failed to reveal any differences in OCRs of genes encoding Foxp3 or HELIOS that were reported to exhibit differential methylation profiles in induced/peripheral $\mathrm{T}_{\text {reg }}$ cells ${ }^{52}$.

We report a role for IL-2 on Foxp $3^{+} \mathrm{T}_{\text {reg }}$ cells that is largely independent of Foxp3-mediated stabilization of $\mathrm{T}_{\text {reg }}$ cells and of their ability to capture IL-2 from activated $\mathrm{T}_{\text {conv }}$ cells. The $\mathrm{Y} 129 \mathrm{H}$ mutation in CD25 prevents optimal folding and/or egress of CD25 to the surface of T cells, translating into decreased binding of IL-2 and subsequent signaling and proliferative response. Two closely comparable models were previously reported: in the first, mutations inside several of key signal transducing cytoplasmic tyrosines of the IL-2R $\beta$ chain disrupted both IL-2 or IL-15 signaling ${ }^{29}$. The second model overexpressed a constitutively active form of the b subunit of the STAT5 TF ${ }^{51}$ on either IL-2R $\beta(C d 122$ $-/-)^{19}$ or IL-2R $\gamma\left(\gamma c^{-/-}\right)$knockout backgrounds ${ }^{11}$. None of these models could differentiate between IL-2 and IL-15, or other $\gamma$ chain-dependent cytokine signaling, confounding interpretation on the roles of high affinity IL-2 signaling. Nevertheless, a rather intriguing finding in both of these settings, as in our model, is that receptor deficient mice did not develop autoimmunity, prompting the idea that $\mathrm{T}_{\text {reg }}$ cells were set to a low IL-2 receptor signaling threshold sufficient for Foxp3 induction and maintenance. Our current results, however, favor a different interpretation in which, when comparable IL- 2 signals are received by $\mathrm{T}_{\text {reg }}$ and $\mathrm{T}_{\text {conv }}$ cells, the development of autoimmunity can be prevented. Yet, if $\mathrm{T}_{\text {reg }}$ cells cannot receive as much IL- 2 signals as $\mathrm{T}_{\text {conv }}$ cells, mice will develop fatal wasting disease. A third model recently developed by Rudensky and colleagues, enabled to discriminate the contribution of IL-2 capture and $\mathrm{T}_{\text {reg }}$ cell stability in preventing fatal autoimmunity ${ }^{40}$. As $\mathrm{T}_{\text {reg }}$ cells cannot secrete IL-2 ${ }^{6}$ but constitutively express the high affinity IL-2R $\alpha / C D 25$ chain, a large conundrum in the field is their reliance on cell-extrinsic IL-2 from activated -potentially autoreactive- $\mathrm{T}_{\text {conv }}$ cells, thus preventing excessive $\mathrm{T}_{\text {conv }}$ cell proliferation and activation by physically capturing the IL-2 they secrete. This study brought strong evidence that IL-2 capture does represent a key mechanism of suppression used by $\mathrm{T}_{\text {reg }}$ cells. While the $\mathrm{Il} 2 \mathrm{ra}^{\mathrm{mut} / \mathrm{mut}}$ mouse does not allow to assess the role of IL- 2 capture by $\mathrm{T}_{\text {reg }}$ cells in maintaining immune homeostasis, the progression of disease and survival in Foxp $3^{y /-}$ mice rescued with $\mathrm{Il} 2 \mathrm{ra}^{\text {mut } / m u t} \mathrm{~T}_{\text {reg }}$ cells, the $\mathrm{Rag}^{-/-}$transfer experiments and the Foxp $3^{\mathrm{y} /-} / \mathrm{Il}_{2} \mathrm{ra}^{\text {mut }} / \mathrm{mut}$ chimeras, are close to that observed in Foxp $3^{y /-}$ mice. Length of survival is, however, distinct to that of the Rudensky model, in which mouse survival is approximately twice increased. In this latter model too, $\mathrm{CD}^{+}$but not $\mathrm{CD} 4^{+} \mathrm{T}$ cells, exhibit robust activation whereas in our Foxp $3^{y /-} / I l 2 \mathrm{ra}^{\text {mut } / m u t}$ chimeras, both subsets of $\mathrm{T}_{\text {conv }}$ cells are highly activated. Altogether, these observations support the idea that altering $\mathrm{T}_{\text {reg }}$ cell epigenetic identity, IL-2 capture and signaling leads to more rapid autoimmunity.

IL-2 therapy has been used for over two decades in patients, initially with the goal to boost anti-tumoral and HIV-specific immunity ${ }^{52,53}$. High doses of IL-2 were mostly used with important side effects and mitigated efficiencies. Yet the use of lower doses of IL-2, with the underlying rationale that $\mathrm{T}_{\text {reg }}$ cells would be more efficiently targeted than effector $\mathrm{T}$ cells, showed a preferential expansion of $\mathrm{T}_{\text {reg }}$ cells both in preclinical models and in type 1 diabetes patients, which was associated with better prognostic markers ${ }^{54,55}$. While the mechanism underlying these promising outcomes in patients may be accounted for by $\mathrm{T}_{\text {reg }}$ cell expansion, our results further raise the possibility that qualitative changes at the levels of chromatin accessibility and epigenetic reprogramming of $\mathrm{T}_{\text {reg }}$ cells during thymic selection, may contribute to ameliorate $\mathrm{T}_{\text {reg }}$ cell functions in autoimmune patients.

\section{Methods}

Ethics statement. This study was carried out in strict accordance with the recommendations by the animal use committees at the Albert Einstein College of 
Medicine. All efforts were made to minimize suffering and provide humane treatment to the animals included in the study.

Mice. All mice were bred in our SPF animal facility at the Albert Einstein College of Medicine. We used wild-type (WT) C57BL/6J (B6) 6-8 weeks old mice, congenic CD45.1 $1^{+/+}$(\#2014), Ccr2 ${ }^{-/-2009}$ (\#4999), Ccr2 $2^{-/-2012}$ (\#4999), Foxp3 $3^{+/-}$ (\#19933), Foxp $3^{R f p / R f p}$ (\#8374), Rag1 ${ }^{-1-}$ (\#2216) from the Jackson labs all on the B6 genetic background. Ccr2 ${ }^{+1+2009} \mathrm{Il}_{2 \mathrm{ra}}{ }^{\text {mut } / m u t}$ (called Il2ra ${ }^{\text {mut } / \mathrm{mut}}$ ) were generated by intercrossing to the B6. Il15 ${ }^{-/-}$(\#4269) mice were purchased from Taconic.

\section{Microbial pathogens and mice infections. We used wild type Listeria} monocytogenes expressing the Ovalbumin (Ova) model antigen ( $L m$-Ova) on the 10403s genetic background ${ }^{56}$. For infections, bacteria were grown to a logarithmic phase in broth heart infusion medium, diluted in PBS to infecting concentration $\left(10^{4}\right)$ and injected i.v. For Herpes Simplex Virus 2 (HSV-2) infection, female mice treated with $2 \mathrm{mg}$ medroxyprogesterone acetate subcutaneously (s.c.) were immunized or not 5 days later intravaginally with $2 \times 10^{5}$ plaque forming units (PFU) of $186 \Delta \mathrm{Kpn} \mathrm{HSV-2} \mathrm{(TK}{ }^{-} \mathrm{HSV}-2$ ) and organs (spleen and draining LNs) were harvested 7 days later.

\section{Cell suspensions for flow cytometry and adoptive transfers. Spleens, lymph} nodes (inguinal and cervical), or thymuses were dissociated on nylon mesh while lungs, liver, and pancreas were cut. All organs were incubated in HBSS medium with $4000 \mathrm{U} / \mathrm{mL}$ collagenase I and $0.1 \mathrm{mg} / \mathrm{mL}$ DNase I, and red blood cells (RBC) lysed with $\mathrm{NH}_{4} \mathrm{Cl}$ buffer $(0.83 \% \mathrm{vol} / \mathrm{vol})$. Blood was harvested into heparin tubes and $\mathrm{RBC}$ lysed as before. Bone marrow cells were obtained from flushing femur with complete RPMI with $10 \%$ FCS

Cell-staining for FACS analysis. Cell suspensions were incubated with 2.4G2 Fc Block and stained with fluorescently tagged antibodies (Abs) purchased from eBioscience, BD Biosciences, Tonbo Bioscience, or BioLegend (Supplementary Table1) in PBS 1\% FCS, 2 mM EDTA, 0.02\% sodium azide. Biotinylated monomers $(1 \mathrm{mg} / \mathrm{mL})$ obtained from the NIH tetramer Core Facility, were conjugated with PE-labeled Streptavidin $(1 \mathrm{mg} / \mathrm{mL})$ as follow: $6.4 \mu \mathrm{L}$ of PE-Streptavidin were added to $10 \mu \mathrm{L}$ of monomers every $15 \mathrm{~min}$ four times on ice. Newly generated tetramers (1/400-1/500 dilution) were then used to stain spleen/LN cells for $1 \mathrm{~h}$ at $4{ }^{\circ} \mathrm{C}$. For transcription factor (TF) intracellular staining (Foxp3, Blimp-1), cells were fixed in eBioscience Fixation/Permeabilization buffer prior to TF Ab staining in eBioscience Permeabilization buffer for $30 \mathrm{~min}$. For intracellular cytokine staining (ICS), cells were incubated $4 \mathrm{~h}$ at $37^{\circ} \mathrm{C} / 5 \% \mathrm{CO}_{2}$ in RPMI1640 10\%FCS, Golgi Plug/Golgi Stop (BD), fixed in IC fixation buffer (eBioscience), and permeabilized prior to $30 \mathrm{~min}$ staining with Abs against indicated intracellular markers. For intracellular phosphorylated STAT5 staining, cells were starved in RPMI w/o FCS for 30 min before stimulation with variable concentration of recombinant human IL-2 (Gemini) for $20 \mathrm{~min}$. Cells were then fixed and permeabilized with 4\% PFA followed by $90 \%$ methanol, and stained with anti-pY-STAT5 antibody (BD Biosciences). Data acquisition was done using a BD LSR II or a FACS Aria III flow cytometer. All flow cytometry data were analyzed using FlowJo v9 software (TreeStar). Cell sorting of Foxp $3^{+}$and Foxp $3^{-}$cells was performed based on RFP expression in Foxp $3^{R f p / R f p}$ reporter mice using a BD FACS Aria III cell sorter. The FACS gating strategies for the experiments shown and T cell sorting are provided in Supplementary Fig. 8.

Transfection of wild-type and Y129H II2ra in 293T cells. The Il2ra cDNA was amplified by PCR and cloned into pMSCV-IRES-GFP (pMIG, kind gift from Guy Sauvageau) to generate pMIG-Il2ra. PCR was performed on PMIG-Il2ra to introduce a point mutation on nucleotide 426 (thymidine to a cytosine), which results in a tyrosine-histidine conversion at amino-acid position 129 . The Il2ramut cDNA was then cloned into PMIG to generate PMIG-Il2ramut. The presence of the introduced point mutation was confirmed by sequencing.

293T cells were plated 2 days before transfection on $100 \mathrm{~mm}$ adherent petri dish at $10^{6}$ cells per plates. Cells at $70 \%$ confluence were transfected with $30 \mu \mathrm{g}$ of the plasmid pMIG, pMIG-Il2ra or pMIG-Il2ra ${ }^{m u t}$ using $45 \mu \mathrm{l}$ Lipofectamine 2000 in $4.5 \mathrm{~mL}$ OptiMEM (ThermoFisher) overnight in antibiotic-free medium. Medium was replaced the day after transfection and 3 days later, cells were trypsinized and analyzed for CD25 extra- and intracellular expression by flow cytometry as described before. The 293T cells were a kind gift from Heather Melichar (University of Montreal, Canada) and were tested mycoplasma negative.

In vitro $\mathbf{T}_{\text {conv }}$ and $\mathbf{T}_{\text {reg }}$ cell assays. For all assays, naive $\mathrm{CD} 4^{+}$or $\mathrm{CD} 8^{+} \mathrm{T}_{\text {conv }}$ cells were negatively selected from spleen and LNs using either anti-CD8 $\beta$ (H35) or anti-CD4 (GK1.5), anti-CD11b (M1/70), anti-MHC-II (M5/114), anti-TER119, anti-B220 (RA3-6B2) and anti-CD25 (PC61), all at $5 \mu \mathrm{g} / \mathrm{mL}$ for $30 \mathrm{~min}$ at $4^{\circ} \mathrm{C}$. Cells were then washed and incubated with anti-rat magnetic beads at 1 bead/target cell for $30 \mathrm{~min}$ at $4{ }^{\circ} \mathrm{C}$ (Dynabeads sheep anti-rat IgG, Invitrogen). For suppression assays, purified naive WT $C d 45.1^{+/+} \mathrm{CD} 4^{+} \mathrm{T}_{\text {conv }}$ cells were stained with $1-5 \mu \mathrm{M}$ of CellTrace Violet (CTV, Invitrogen) according to the manufacturer's protocol. WT and Il2ra ${ }^{\text {mut/mut }}$ Foxp $3^{R f p / R f p} \mathrm{~T}_{\text {reg }}$ cells were sorted by flow cytometry (Aria III).
$5 \times 10^{4} \mathrm{CTV}$-labeled naive $\mathrm{CD} 4^{+} \mathrm{T}_{\text {conv }}$ cells were cultured with increasing numbers of $\mathrm{T}_{\text {reg }}$ cells in the presence of $10^{5}$ irradiated, T cell-depleted WT B6 splenocytes and $1 \mu \mathrm{g} / \mathrm{mL}$ anti-CD3e (clone $145-2 \mathrm{C} 11, \mathrm{BD}$ ) in a 96 round-bottom plate for $72 \mathrm{~h}$. Cell proliferation of $\mathrm{T}_{\text {conv }}$ cells (live $\mathrm{CFSE}^{-} \mathrm{CD} 4^{+} \mathrm{Foxp}^{-}$) was determined by flow cytometry based on CTV fluorescence intensity dilution of $\mathrm{T}_{\text {conv }}$ cells. For proliferation assays, CTV-labeled purified WT and Il2ramut/mut naive $\mathrm{CD} 4^{+}$or $\mathrm{CD} 8^{+}$ $\mathrm{T}_{\text {conv }}$ cells were incubated for $24 \mathrm{~h}$ on anti-CD3ع $(10 \mu \mathrm{g} / \mathrm{mL})$ pre-coated wells before co-culture for $96 \mathrm{~h}$ with varied concentrations $\left(2.5-10^{4} \mathrm{U} / \mathrm{mL}\right)$ of human recombinant IL-2 (Gemini Bio-product). Cell proliferation was determined by flow cytometry and CTV fluorescence dilution of $\mathrm{T}_{\text {conv }}$ cells. For short-term activation assays for immunofluorescence, purified WT and $\mathrm{Il}_{2} \mathrm{ra}^{\mathrm{mut} / \mathrm{mut}}$ naive $\mathrm{CD} 4^{+} \mathrm{T}$ cells were incubated for $48 \mathrm{~h}$ with anti-CD3ع $(10 \mu \mathrm{g} / \mathrm{mL})$ pre-coated wells to induce $\mathrm{CD} 25$ upregulation. At $48 \mathrm{~h}$, cells were transferred in polylysine pre-coated chambers, left to adhere for $1 \mathrm{~h}$ at $37^{\circ} \mathrm{C}$, fixed with $1 \% \mathrm{PFA}$ and permeabilized with $0.1 \%$ Triton X-100 prior to OVN staining in PBS 0.5\% BSA, 0.05\% Triton X-100 containing polyclonal goat anti-mouse CD25 (RD systems) and rabbit anticalreticulin Abs (1/300 dilution, ThermoFisher, PA3-900). Staining was revealed by staining for $2 \mathrm{~h}$ with secondary anti-goat-Alexa 488 and anti-rabbit-Alexa $546 \mathrm{Abs}$ (Invitrogen). Cells were then covered with Fluoromount-G (SouthernBiotech) and imaged using a Zeiss Axiovert microscope (Carl Zeiss Microimaging Inc., Thornwood, NY) with a $\times 63$ NA 1.4 objective and a Retiga 2000 camera. Green channel images using a 450-490 excitation/500-550 emission bandpass filter and red staining was imaged with a 565/30 excitation-620/60 emission bandpass filter Images were processed using Adobe Photoshop CS 4 (Adobe Systems, Inc. San Jose, CA).

In vivo $\mathbf{T}_{\text {reg }}$ cell functional assays. For mixed bone-marrow chimera mice, Rag1 ${ }_{-1-} C d 45.2^{+/+}$mice were lethally irradiated with 1200 rads before immediate reconstitution with $5 \times 10^{6} \mathrm{~T}$ cell-depleted (as for the in vitro assays) bone marrow from Foxp $3^{-/ y} C d 45.1^{+/+}$and Il2ra ${ }^{m u t / m u t} C d 45.1^{+/-}$or congenic $C d 45.1^{+/+}$and $\mathrm{Il} 2 \mathrm{ra}^{\mathrm{mut} / \mathrm{mut}} \mathrm{Cd} 45.1^{+/-}$at a 1:1 ratio. Mice were placed under antibiotics for 2 weeks and reconstitution ratios were checked by FACS $4-6$ weeks later. In some experiments, C57BL/6 Cd45.2 $2^{+/+}$were used as recipient. In such case, mice received $150 \mu \mathrm{g}$ of anti-CD8 $\beta$ and anti-CD4 i.v. with for two consecutive days to deplete $\mathrm{T}$ cells prior irradiation.

For Rag1 ${ }^{-1-} \mathrm{T}$ cell transfers, $\mathrm{LN}$ - and spleen-purified naive $\mathrm{CD} 4^{+} \mathrm{T}_{\text {conv }}$ cells (by negative selection as above) isolated from Cd45.1+l+ male mice were transferred to $\mathrm{Rag1}^{-/-}$recipients alone or mixed at a 5:1 ratio with flow-sorted sorted (Aria III) RFP ${ }^{+} \mathrm{T}_{\text {reg }}$ cells from spleen and LNs of WT or Il2ra ${ }^{\text {mut } / m u t}$ Foxp $3^{R f p / R f p}$ reporter mice $\left(2.5 \times 10^{6}\right.$ cells per recipient). In some experiments (when indicated), naive $\mathrm{CD} 4^{+} \mathrm{T}$ cells were labeled with $10 \mathrm{nM}$ of CTV prior adoptive transfer. Recipient mice were monitored for body weight changes and transferred lymphocyte subsets were monitored by flow cytometry 45 and 75 days later.

For Foxp $3^{-1 y}$ mice rescue experiments, $10^{6}$ flow-sorted $\mathrm{T}_{\text {reg }}$ cells from WT or Il2ra ${ }^{\text {mut } / m u t}$ Foxp $3^{R f p / R f p}$ reporter mice were injected i.p. into 1-2-day-old pups (Foxp $3^{y /-}$ males, genotyped after birth) from females Foxp $3^{+/-}$mice bred with Cd45. $1^{+/+}$congenic males. Male pups were assessed for the development of lymphoproliferative syndrome in blood and LNs at $~ 30$ days of age.

For the antibody neutralization treatment, mice were given $150 \mu \mathrm{g}$ of antiICOSL (clone HK5.3, BioXcell) by i.v. injection on days $0,3,6,9$, and 12 and sacrificed on day 14 .

Histological analysis. Tissue samples were fixed in $10 \%$ neutral buffered formalin and processed for hematoxylin and eosin staining. For each organ collected and for each genotype, two sections were cuts at $100 \mu \mathrm{m}$ apart and all slides were scanned using a P250 High Capacity Slide Scanner (Perkin Elmer).

\section{Microarrays. Overall, $50,000 \mathrm{RFP}^{+} \mathrm{T}_{\text {reg }}$ or naive $\left(\mathrm{CD} 62 \mathrm{~L}^{\text {hi }} \mathrm{CD} 44^{\mathrm{lo}}\right)$}

$\mathrm{RFP}^{\text {neg }} \mathrm{CD} 25^{\text {neg }} \mathrm{CD} 4^{+} \mathrm{T}_{\text {conv }}$ cells from LNs of WT or Il2ra $a^{\text {mut/mut }}$ Foxp $3^{\text {Rfp/Rfp mice }}$ were flow-sorted based on the RFP signal and indicated markers after enrichment for $\mathrm{CD} 4^{+} \mathrm{T}$ cells (using negative selection, as described above). Pelleted cells were stored in $700 \mu \mathrm{L}$ of TRIzol (Life Technologies) at $-80^{\circ} \mathrm{C}$ until RNA extraction. Total RNA was extracted using the RNAeasy Micro kit with RNase-Free DNase Set (Qiagen) according to the manufacturer protocol. The quality score and quantity of purified RNA was assessed with a Bioanalyzer RNA 6000 Pico Chip (Agilent). Total RNA was then converted to cDNA, amplified and hybridized to Affymetrix Mouse Transcriptome Array 1.0 Pico. Raw CEL files were preprocessed and normalized using Affymetrix Expression Console (version 1.4.1.46) and resulting data were analyzed with the Affymetrix Transcriptome Analysis Console (version 3.1.0.5). We calculated fold-differences between experimental groups and tested significance using one-way ANOVA (unpaired). Significantly up and downregulated genes were defined with at least a 1.5 -fold expression difference and a $p$ value $\leq 0.01$. Over-representation of biological-process (BP) gene-ontology (GO) terms was calculated using BiNGO (version 3.0.3) in Cytoscape (version v3.4.0), employing the hypergeometric test and applying a significance cutoff of FDRadjusted $p$-value $\leq 0.05$. The GO ontology and annotation files used were downloaded on May. 25, 2017. The output of BiNGO was imported into EnrichmentMap (version 2.1.0) in Cytoscape to cluster redundant GO terms and visualize the 
results. An EnrichmentMap was generated using a Jaccard similarity coefficient cutoff of 0.4, a $p$-value cutoff of 0.001, an FDR-adjusted cutoff of 0.005 , and excluding gene sets with fewer than 5 genes. The network was visualized using a perfuse force-directed layout with default settings and 500 iterations. Groups of similar GO terms were manually circled. Finally, for analysis of gene expression in thymocyte fractions shown in Supplementary Fig. 5c, raw data from the NCBI database (GEO GSE15907) were analyzed ${ }^{41}$.

Epigenetic profiling. For ATAC-seq experiments, we performed the analysis on two (LNs) or four (thymus) biological replicates per group as previously described $^{35}$. Briefly, nuclei were isolated from $50,000 \mathrm{CD} 4^{+} \mathrm{T}$ cell-enriched (by negative selection) flow-sorted $\mathrm{RFP}^{+} \mathrm{T}_{\text {reg }}$ cells from WT or Il2ramut/mut Foxp $3^{R f p / R f p}$ mice (LNs or thymus) using a solution of $10 \mathrm{mM}$ Tris- $\mathrm{HCl}, 10 \mathrm{mM} \mathrm{NaCl}, 3 \mathrm{mM} \mathrm{MgCl}$, and $0.1 \%$ IGEPAL CA-630. Immediately following nuclei isolation, the transposition reaction was conducted using Tn5 transposase and TD buffer (Illumina) for $45 \mathrm{~min}$ at $37^{\circ} \mathrm{C}$. Transposed DNA fragments were purified using Qiagen MiniElute Kit and PCR amplified using NEB Next High Fidelity $2 \times$ PCR master mix (New England Labs) with dual indexes primers (Illumina Nextera).

For SATB1 ChIP-seq experiments, we performed the ChIP-seq following the Mayers Lab ChIP-seq Protocol v011014 which is one of the suggested protocols by ENCODE project with slight modifications (https://www.encodeproject.org/ documents/6ecd8240-a351-479b-9de6-f09ca3702ac3/@@download/attachment/ ChIP-seq_Protocol_v011014.pdf). Single positive (SP) CD4 $4^{+}$thymocytes from thymus of WT and Il2ra ${ }^{\mathrm{mut} / \mathrm{mut}}$ mice on two biological replicates were pre-enriched by negative selection using anti-CD8 3 (H35), anti-MHC-II (M5/114), anti-CD11b (M1/70) and anti-TER119. After staining the remaining cells with fluorescent labeled antibodies against CD4 (GK1.5) and CD8 $\alpha$ (53-6.7), we flow-sorted $2 \times 10^{6}$ $\mathrm{CD} 4^{+} \mathrm{CD} 8 a^{\text {neg }} \mathrm{SP}$ thymocytes. Sorted cells were next cross-linked in $1 \%(\mathrm{wt} / \mathrm{vol})$ formaldehyde solution for 30 min. Cross-linked DNA was lysed in Farnham lysis buffer (5 mM PIPES pH 8.0, $85 \mathrm{mM} \mathrm{KCl}$ and $0.5 \% \mathrm{NP}-40$ ), fragmented in RIPA buffer ( $1 \%$ NP- $40,0.5 \%$ sodium deoxycholate, and $0.1 \%$ SDS in $1 \times \mathrm{PBS})$ using Bioruptor (Diagenode), and incubated overnight at $4{ }^{\circ} \mathrm{C}$ with $100 \mu \mathrm{L}$ of DynaBeads M-280 Sheep anti-Rabbit IgG magnet beads (Invitrogen) preincubated with $20 \mu \mathrm{g}$ of anti-SATB1 antibody (Abcam, ab70004). Beads were washed five times with LiCl wash buffer $(100 \mathrm{mM}$ Tris $\mathrm{pH} 7.5,500 \mathrm{mM} \mathrm{LiCl}, 1 \% \mathrm{NP}-40$ and $1 \%$ sodium deoxycholate) and one time with $10 \mathrm{mM}$ Tris/0.1 M EDTA. SATB1-bound DNA was then eluted from the beads and reverse cross-linked by incubating the beads pellet in $200 \mu \mathrm{l}$ of IP elution buffer (1\% SDS and $\left.0.1 \mathrm{M} \mathrm{NaHCO}_{3}\right)$ at $65^{\circ} \mathrm{C}$ overnight and further purified with MinElute PCR Purification Kit (QIAGEN). The library was prepared using Accel-NGS 2 S Plus DNA library kit according to the manufacturer's instructions.

Sequencing libraries processing. The size distribution and molarity of the sequencing library were determined by using an Bioanalyzer analysis (High Sensitivity DNA chip, Agilent). Sequencing was performed using a HiSeq 2500 system (Illumina). Obtained sequences were mapped to the mouse mm10 reference genome using BWA mem ${ }^{57,58}$. After eliminating duplicated reads and the reads aligned to mitochondrial DNA, we kept only concordantly mapped pairs for further analysis. Peak calling was performed on shifted reads using MACS v2.1 with narrow peaks option to identify areas of sequence tag enrichment following the original report ${ }^{35}$. For ATAC-seq, read1 reads were shifted using bedtools2, as previously performed in Buenestro et al..$^{35}$, before calling peaks for each replicate. We performed Irreproducible Discovery Rate analysis for finding reproducible peaks among the biological replicates $(0.05 \text { cutoff })^{59}$. Analysis was performed in $\mathrm{R}$ (the R project) using Bioconductor packages. The genomic locations, overlapping or nearest genes and finding overlapping peaks between groups were annotated with ChIPpeakAnno ${ }^{60}$ and ChIPseeker ${ }^{61}$ using TxDb.Mmusculus.UCSC.mm10. knownGene annotation (Bioconductor). The motif analysis was performed on the genomic sequences of peaks using MEME-ChIP ${ }^{63}$ and HOMER ${ }^{62}$. Overrepresentation of biological-process BP-GO terms was calculated using BiNGO as described above. For the ATAC-seq data analysis, the output of BiNGO was further filtered by selecting GO with an FDR-adjusted cutoff $<0.001$ and excluding gene sets with fewer than five genes. The list of BP-GO was then imported into REViGO using a similarity coefficient of 0.7 and the SimRel columns to generate semantic similarities scores. The scored terms were visualized in semantic similarity-based scatterplots. For the SATB1 ChIP-seq data analysis, the output of BiNGO was imported into EnrichmentMap (version 2.1.0) in Cytoscape to cluster redundant GO terms and visualize the results as described above.

Statistics. Statistical significance was calculated using an unpaired Student $t$ test with GraphPad Prism software and two-tailed P values are given as: $\left(^{*}\right) p<0.1 ;(* *)$ $p<0.01 ;\left(^{* * *}\right) p<0.001 ;\left(^{* * *}\right) p<0.0001$ and (ns) $p>0.1$. All $p$ values of 0.05 or less were considered significant and are referred to as such in the text. Error bars are mean \pm SEM in all figures.

\section{Data availability}

The accession number for microarrays, ATAC-seq, and ChIP-seq data reported in this paper underlying Figs. 3-5 and Supplementary Figs 3-5 is GEO: GSE103217. The authors declare that all other data supporting the findings of this study are available within the paper and its supplementary information files. A reporting summary Article is available as a Supplementary Information file. The source data underlying Figs. 1a, c, d, g, h, 2a-e, 6a, c-f and 7a, b, d, e, j, k and Supplementary Figs $1 b, d, 2 b, d, 4 c, 6 b-d, f$ and $7 a, b, f, g$ are provided as a Source Data file.

Received: 14 June 2018 Accepted: 27 November 2018

Published online: 18 December 2018

\section{References}

1. Ohkura, N., Kitagawa, Y. \& Sakaguchi, S. Development and maintenance of regulatory T cells. Immunity 38, 414-423 (2013).

2. van der Veeken, J., Arvey, A. \& Rudensky, A. Transcriptional control of regulatory T-cell differentiation. Cold Spring Harb. Symp. Quant. Biol. 78, 215-222 (2013).

3. Benoist, C. \& Mathis, D. Treg cells, life history, and diversity. Cold Spring Harb. Perspect. Biol. 4, a007021 (2012).

4. Josefowicz, S. Z., Lu, L. F. \& Rudensky, A. Y. Regulatory T cells: mechanisms of differentiation and function. Annu. Rev. Immunol. 30, 531-564 (2012).

5. Fontenot, J. D., Gavin, M. A. \& Rudensky, A. Y. Foxp3 programs the development and function of CD4+ CD25+ regulatory T cells. Nat. Immunol. 4, 330-336 (2003).

6. Hori, S., Nomura, T. \& Sakaguchi, S. Control of regulatory T cell development by the transcription factor Foxp3. Science 299, 1057-1061 (2003).

7. Khattri, R., Cox, T., Yasayko, S. A. \& Ramsdell, F. An essential role for Scurfin in CD4+CD25+ T regulatory cells. Nat. Immunol. 4, 337-342 (2003).

8. Bennett, C. L. et al. The immune dysregulation, polyendocrinopathy, enteropathy, X-linked syndrome (IPEX) is caused by mutations of FOXP3. Nat. Genet. 27, 20-21 (2001).

9. Sekiya, T. et al. Nr4a receptors are essential for thymic regulatory T cell development and immune homeostasis. Nat. Immunol. 14, 230-237 (2013).

10. Josefowicz, S. Z. \& Rudensky, A. Control of regulatory T cell lineage commitment and maintenance. Immunity 30, 616-625 (2009).

11. Burchill, M. A. et al. Linked T cell receptor and cytokine signaling govern the development of the regulatory $\mathrm{T}$ cell repertoire. Immunity 28, 112-12 (2008).

12. Hill, J. A. et al. Foxp3 transcription-factor-dependent and -independent regulation of the regulatory $\mathrm{T}$ cell transcriptional signature. Immunity 27 , 786-800 (2007).

13. Lio, C. W. \& Hsieh, C. S. A two-step process for thymic regulatory T cell development. Immunity 28, 100-111 (2008).

14. Gavin, M. A. et al. Foxp3-dependent programme of regulatory T-cell differentiation. Nature 445, 771-775 (2007).

15. Rudra, D. et al. Runx-CBFbeta complexes control expression of the transcription factor Foxp3 in regulatory T cells. Nat. Immunol. 10, 1170-1177 (2009).

16. Fu, W. et al. A multiply redundant genetic switch 'locks in' the transcriptional signature of regulatory T cells. Nat. Immunol. 13, 972-980 (2012).

17. Zheng, Y. et al. Role of conserved non-coding DNA elements in the Foxp3 gene in regulatory T-cell fate. Nature 463, 808-812 (2010).

18. Feng, $\mathrm{Y}$. et al. Control of the inheritance of regulatory $\mathrm{T}$ cell identity by a cis element in the Foxp3 locus. Cell 158, 749-763 (2014).

19. Burchill, M. A., Yang, J., Vogtenhuber, C., Blazar, B. R. \& Farrar, M. A. IL-2 receptor beta-dependent STAT5 activation is required for the development of Foxp3+ regulatory T cells. J. Immunol. 178, 280-290 (2007).

20. Malek, T. R. The biology of interleukin-2. Annu. Rev. Immunol. 26, 453-479 (2008).

21. Fontenot, J. D., Rasmussen, J. P., Gavin, M. A. \& Rudensky, A. Y. A function for interleukin 2 in Foxp3-expressing regulatory T cells. Nat. Immunol. 6, 1142-1151 (2005)

22. D'Cruz, L. M. \& Klein, L. Development and function of agonist-induced CD25 + Foxp3+ regulatory T cells in the absence of interleukin 2 signaling. Nat. Immunol. 6, 1152-1159 (2005).

23. Setoguchi, R., Hori, S., Takahashi, T. \& Sakaguchi, S. Homeostatic maintenance of natural Foxp3(+) CD25(+) CD4(+) regulatory T cells by interleukin (IL)-2 and induction of autoimmune disease by IL-2 neutralization. J. Exp. Med. 201, 723-735 (2005).

24. Ohkura, N. et al. T cell receptor stimulation-induced epigenetic changes and Foxp3 expression are independent and complementary events required for Treg cell development. Immunity 37, 785-799 (2012).

25. Lin, W. et al. Regulatory $\mathrm{T}$ cell development in the absence of functional Foxp3. Nat. Immunol. 8, 359-368 (2007).

26. Samstein, R. M. et al. Foxp3 exploits a pre-existent enhancer landscape for regulatory T cell lineage specification. Cell 151, 153-166 (2012).

27. Kitagawa, Y. et al. Guidance of regulatory $\mathrm{T}$ cell development by Satb1dependent super-enhancer establishment. Nat. Immunol. 18, 173-183 (2017). 
28. Placek, K. et al. MLL4 prepares the enhancer landscape for Foxp3 induction via chromatin looping. Nat. Immunol. 18, 1035-1045 (2017).

29. Yu, A., Zhu, L., Altman, N. H. \& Malek, T. R. A low interleukin-2 receptor signaling threshold supports the development and homeostasis of $\mathrm{T}$ regulatory cells. Immunity 30, 204-217 (2009).

30. Boring, L., Gosling, J., Cleary, M. \& Charo, I. F. Decreased lesion formation in CCR2-/- mice reveals a role for chemokines in the initiation of atherosclerosis. Nature 394, 894-897 (1998).

31. Bruhl, H. et al. Dual role of CCR2 during initiation and progression of collagen-induced arthritis: evidence for regulatory activity of CCR2+ T cells. J. Immunol. 172, 890-898 (2004).

32. Zhang, N. et al. Regulatory $\mathrm{T}$ cells sequentially migrate from inflamed tissues to draining lymph nodes to suppress the alloimmune response. Immunity $\mathbf{3 0}$, 458-469 (2009).

33. Obar, J. J. et al. $\mathrm{CD} 4+\mathrm{T}$ cell regulation of $\mathrm{CD} 25$ expression controls development of short-lived effector CD8 $+\mathrm{T}$ cells in primary and secondary responses. Proc. Natl Acad. Sci. USA 107, 193-198 (2010).

34. Cheng, G., Yu, A., Dee, M. J. \& Malek, T. R. IL-2R signaling is essential for functional maturation of regulatory $\mathrm{T}$ cells during thymic development. J. Immunol. 190, 1567-1575 (2013).

35. Buenrostro, J. D., Giresi, P. G., Zaba, L. C., Chang, H. Y. \& Greenleaf, W. J. Transposition of native chromatin for fast and sensitive epigenomic profiling of open chromatin, DNA-binding proteins and nucleosome position. Nat. Methods 10, 1213-1218 (2013).

36. van der Veeken, J. et al. Memory of inflammation in regulatory T cells. Cell 166, 977-990 (2016).

37. Scott-Browne, J. P. et al. Dynamic changes in chromatin accessibility occur in CD8+ T cells responding to viral infection. Immunity 45, 1327-1340 (2016).

38. Sen, D. R. et al. The epigenetic landscape of T cell exhaustion. Science 354, 1165-1169 (2016).

39. Pauken, K. E. et al. Epigenetic stability of exhausted T cells limits durability of reinvigoration by PD-1 blockade. Science 354, 1160-1165 (2016).

40. Chinen, T. et al. An essential role for the IL-2 receptor in Treg cell function. Nat. Immunol. 17, 1322-1333 (2016).

41. Mingueneau, M. et al. The transcriptional landscape of alphabeta $\mathrm{T}$ cell differentiation. Nat. Immunol. 14, 619-632 (2013).

42. Ono, M. et al. Foxp3 controls regulatory T-cell function by interacting with AML1/Runx1. Nature 446, 685-689 (2007).

43. Rudra, D. et al. Transcription factor Foxp3 and its protein partners form a complex regulatory network. Nat. Immunol. 13, 1010-1019 (2012).

44. Yasui, D., Miyano, M., Cai, S., Varga-Weisz, P. \& Kohwi-Shigematsu, T. SATB1 targets chromatin remodelling to regulate genes over long distances. Nature 419, 641-645 (2002).

45. Herman, A. E., Freeman, G. J., Mathis, D. \& Benoist, C. CD4+CD25+ T regulatory cells dependent on ICOS promote regulation of effector cells in the prediabetic lesion. J. Exp. Med. 199, 1479-1489 (2004).

46. Smigiel, K. S. et al. CCR7 provides localized access to IL-2 and defines homeostatically distinct regulatory T cell subsets. J. Exp. Med. 211, 121-136 (2014).

47. Lee, H. M., Bautista, J. L., Scott-Browne, J., Mohan, J. F. \& Hsieh, C. S. A broad range of self-reactivity drives thymic regulatory $\mathrm{T}$ cell selection to limit responses to self. Immunity 37, 475-486 (2012).

48. Schuster, M. et al. IkappaB(NS) protein mediates regulatory $\mathrm{T}$ cell development via induction of the Foxp3 transcription factor. Immunity 37, 998-1008 (2012)

49. Wohlfert, E. A. et al. GATA3 controls Foxp3 $(+)$ regulatory T cell fate during inflammation in mice. J. Clin. Invest. 121, 4503-4515 (2011).

50. Ouyang, W. et al. Foxo proteins cooperatively control the differentiation of Foxp3+ regulatory T cells. Nat. Immunol. 11, 618-627 (2010).

51. Burchill, M. A. et al. Distinct effects of STAT5 activation on CD4+ and CD8+ $\mathrm{T}$ cell homeostasis: development of $\mathrm{CD} 4+\mathrm{CD} 25+$ regulatory $\mathrm{T}$ cells versus CD8+ memory T cells. J. Immunol. 171, 5853-5864 (2003).

52. Rosenberg, S. A. et al. Observations on the systemic administration of autologous lymphokine-activated killer cells and recombinant interleukin-2 to patients with metastatic cancer. N. Engl. J. Med. 313, 1485-1492 (1985).

53. Group, I.-E. S. et al. Interleukin-2 therapy in patients with HIV infection. N. Engl. J. Med. 361, 1548-1559 (2009).

54. Dwyer, C. J., Ward, N. C., Pugliese, A. \& Malek, T. R. Promoting immune regulation in type 1 Diabetes using low-dose interleukin-2. Curr. Diab. Rep. 16, 46 (2016).

55. Rosenzwajg, M. et al. Low-dose interleukin-2 fosters a dose-dependent regulatory T cell tuned milieu in T1D patients. J. Autoimmun. 58, 48-58 (2015).

56. Pope, C. et al. Organ-specific regulation of the CD8 T cell response to Listeria monocytogenes infection. J. Immunol. 166, 3402-3409 (2001).
57. Heng, L. Aligning Sequence Reads, Clone Sequences and Assembly Contigs with $B W A-M E M$ (Oxford University Press, Oxford, 2013).

58. Zhu, L. J. et al. ChIPpeakAnno: a Bioconductor package to annotate ChIP-seq and ChIP-chip data. BMC Bioinformatics 11, 237 (2010).

59. Landt, S. G. et al. ChIP-seq guidelines and practices of the ENCODE and modENCODE consortia. Genome Res. 22, 1813-1831 (2012).

60. Machanick, P. \& Bailey, T. L. MEME-ChIP: motif analysis of large DNA datasets. Bioinformatics 27, 1696-1697 (2011).

61. Yu, G., Wang, L. G. \& He, Q. Y. ChIPseeker: an R/Bioconductor package for ChIP peak annotation, comparison and visualization. Bioinformatics 31, 2382-2383 (2015)

62. Heinz, S. et al. Simple combinations of lineage-determining transcription factors prime cis-regulatory elements required for macrophage and B cell identities. Mol. Cell 38, 576-589 (2010).

\section{Acknowledgements}

$\mathrm{H} 2-\mathrm{K}^{\mathrm{b}} / \mathrm{OVA}_{257-264}$ and $\mathrm{H} 2-\mathrm{Kb} / \mathrm{gB}_{498-505}$ tetramers were obtained from the NIH Tetramer Facility. We are grateful to M. Levy (Einstein) for privileged access to the FACS Aria III and thank the AECOM FACS and genomic core facilities. We thank the Lauvau laboratory members and S. Soudja for critical comments, and JF Daudelin for characterizing the transient CD25 transfectants. This work was funded by the National Institute of Health Grants (NIH) AI103338, Hirschl Caulier Award to G.L.; the Canadian Institutes of Health Research Grants PJT-149023 and PJT-152988 to N.L. L.C. received fellowships from ARC, Fondation Bettencourt-Schuller, and the American Association of Immunology (AAI). T.M.W. and S.S.C. were supported by NIH training Grant T32A170117. L.O. received a studentship from the Fonds de recherche du Québec-Santé Core resources for FACS were supported by the Einstein Cancer Center (NCI cancer center support grant 2P30CA013330)

\section{Author contributions}

L.C. designed, performed, and interpreted most experiments, designed and assembled figures, and contributed to editing of the manuscript. M.S. conducted and guided ChIPseq experiments with L.C., performed analysis of all ATAC-seq, ChIP-seq, and microarray data, contributed to data production and interpretation for the corresponding figures and manuscript editing. S.S.C. contributed to sequencing sample processing, manuscript, and figure editing and reorganization. T.M.W. and E.L.S. conducted the fluorescent microscopy experiments and image acquisition. L.O. and N.L. did the $\mathrm{Y} 129 \mathrm{H}$ mutagenesis of WT Il2ra and transient transfections and analysis. N.L. contributed to manuscript editing and discussions. G.L. designed and interpreted all experiments and data with L.C. and all authors, contributed to figure design and editing, and wrote the paper.

\section{Additional information}

Supplementary Information accompanies this paper at https://doi.org/10.1038/s41467 018-07806-6.

Competing interests: The authors declare no competing interests.

Reprints and permission information is available online at http://npg.nature.com/ reprintsandpermissions/

Journal peer review information: Nature Communications thanks the anonymous reviewers for their contribution to the peer review of this work. [Peer reviewer reports are available.]

Publisher's note: Springer Nature remains neutral with regard to jurisdictional claims in published maps and institutional affiliations.

(c) (1) Open Access This article is licensed under a Creative Commons Attribution 4.0 International License, which permits use, sharing, adaptation, distribution and reproduction in any medium or format, as long as you give appropriate credit to the original author(s) and the source, provide a link to the Creative Commons license, and indicate if changes were made. The images or other third party material in this article are included in the article's Creative Commons license, unless indicated otherwise in a credit line to the material. If material is not included in the article's Creative Commons license and your intended use is not permitted by statutory regulation or exceeds the permitted use, you will need to obtain permission directly from the copyright holder. To view a copy of this license, visit http://creativecommons.org/ licenses/by/4.0/.

(C) The Author(s) 2018 